\title{
UK Renal Registry 19th Annual Report: Chapter 2 UK Renal Replacement Therapy Prevalence in 2015: National and Centre-specific Analyses
}

\author{
Stephanie J MacNeilla ${ }^{a}$ Daniel Ford ${ }^{b}$

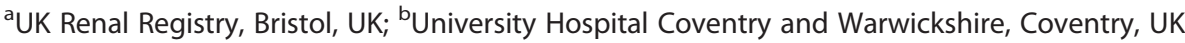

\section{Keywords}

Chronic kidney disease - Clinical Commissioning Group • Comorbidity · Diabetes · Dialysis · End stage renal disease . Established renal failure · Ethnicity · Haemodialysis · Peritoneal dialysis . Prevalence - Renal replacement therapy . Transplantation · Treatment modality

\section{Summary}

- There were 61,256 adult patients receiving renal replacement therapy (RRT) in the UK on 31st December 2015, an absolute increase of 3.9\% from 2014.

- The actual number of patients increased by 3.6\% for haemodialysis (HD), 4.7\% for those with a functioning transplant but decreased by $0.8 \%$ for peritoneal dialysis (PD).

- The UK adult prevalence of RRT was 941 per million population ( $\mathrm{pmp}$ ). The reported prevalence in 2000 was 523 pmp.
- The number of patients receiving home HD decreased slightly from 1,195 patients in 2014 to 1,175 patients in 2015 .

- The median age of prevalent patients was 59 years (HD 67 years, PD 64 years, transplant 54 years). In 2000 the median age was 55 years (HD 63 years, PD 58 years, transplant 48 years). The percentage of RRT patients aged greater than 75 years in 2015 was $16.1 \%$.

- For all ages, RRT prevalence in men exceeded that in women, peaking in age group 75-79 years at 3,074 pmp in men and at 1,589 pmp in women.

- The most common identifiable renal diagnosis was glomerulonephritis (19\%), followed by diabetes $(16 \%)$, other (16\%) and aetiology uncertain (16\%).

- Transplantation continued as the most common treatment modality (53\%), HD was used in $41 \%$ and PD in $6 \%$ of RRT patients.

- RRT prevalence in patients aged $\geqslant 85$ years continued to increase between 2014 and 2015 (1,060 to 1,084 per million age related population).

\section{KARGER}

Fax +4161306 1234 E-Mail karger@karger.com www.karger.com/nef
This article is licensed under the Creative Commons AttributionNonCommercial-NoDerivatives 4.0 International License (CC BYNC-ND) (http://www.karger.com/Services/OpenAccessLicense). Usage and distribution for commercial purposes as well as any
distribution of modified material requires written permission.
Stephanie MacNeill

UK Renal Registry, Southmead Hospital, Southmead Road, Bristol, BS10 5NB, UK

Email: renalregistry@renalregistry.nhs.uk 


\section{Introduction}

This chapter presents data on all adult patients on RRT in the UK at the end of 2015. The UK Renal Registry (UKRR) received data returns for 2015 from all five renal centres in Wales, all five in Northern Ireland and 51 in England. Cambridge (Addenbrooke's) renal centre were unable to submit their 2015 data at patient level by the close of the data collection period. The centre was able to submit summary numbers of patients on RRT at the end of 2015 by treatment modality. Data from all nine centres in Scotland were obtained from the Scottish Renal Registry. Demographic data on children and young adults can be found in chapter 4 .

These analyses of prevalent RRT patients are performed annually to aid clinicians and policy makers in planning future RRT requirements in the UK. It is important to understand national, regional and centre level variation in numbers of prevalent patients as part of the capacity planning process. In addition, knowledge about variation in case mix is also reported to improve understanding of where resources should be focussed to improve equity of provision of RRT in the UK.

The term established renal failure (ERF) used within this chapter is synonymous with the terms end stage renal failure and end stage renal disease, which are in more widespread international usage. Patients have disliked the term 'end stage' which reflects the inevitable outcome of this disease.

\section{Methods}

Crude prevalence ratios were calculated per million population (pmp) and age/gender standardised prevalence ratios were calculated as detailed in appendix D: Methodology used for Analyses of Clinical Commissioning Group (CCG)/Health Board (HB) Incidence and Prevalence Rates and of Standardised Ratios. (www.renalreg.org).
Throughout this chapter, haemodialysis refers to all modes of HD treatment, including haemodiafiltration (HDF). Several centres reported significant numbers of patients on HDF, but other centres did not differentiate this treatment type in their UKRR returns. Where joint care of renal transplant recipients between the referring centre and the transplant centre occurred, the patient was usually allocated to the referring centre (see appendix B2 for the allocation procedure). Thus the number of patients allocated to a transplant centre is often lower than that recorded by the centre itself and as a converse pre-emptively transplanted patients are sometimes allocated to the transplanting centre rather than the referring centre if no transfer out code had been received. Queries and updated information are welcomed by the UKRR at any point during the year if this has occurred.

Prevalent patients on RRT in 2015 were examined by time on RRT, age group, gender, ethnic origin, primary renal disease, presence of diabetes and treatment modality (see appendix $\mathrm{H}$ : Coding) (www.renalreg.org). In the analysis of prevalence, only adult patients on RRT contributed to the numerator and denominator.

Time on RRT was defined as median time on treatment and was calculated from the most recent start date. Patients without an accurate start date were excluded from this calculation.

Analyses were done for the UK as a whole, by UK country, at centre level and split by treatment modality when appropriate. Cambridge is excluded from centre level prevalent analyses.

Chi-squared test, Fisher's exact test, linear regression and Kruskal Wallis tests were used as appropriate to test for significant differences between groups. The data were analysed using SAS 9.3.

\section{Results}

Prevalent patient numbers and changes in prevalence

The number of patients for each country (table 2.1) was calculated by adding the number of patients in each renal centre located in the country. These differ marginally from those quoted elsewhere in this report, however, when patients are allocated to geographical areas by their individual postcodes, as some centres treat patients across national boundaries.

Table 2.1. Prevalence of adult RRT in the UK on $31 / 12 / 2015$

\begin{tabular}{|c|c|c|c|c|c|}
\hline & England & $\mathrm{N}$ Ireland & Scotland & Wales & UK \\
\hline Number of prevalent patients & 51,672 & 1,701 & 4,853 & 3,030 & 61,256 \\
\hline Total estimated population, mid-2015 (millions) ${ }^{*}$ & 54.8 & 1.9 & 5.4 & 3.1 & 65.1 \\
\hline Prevalence ratios HD (pmp) & 389 & 336 & 358 & 368 & 384 \\
\hline Prevalence ratios PD (pmp) & 56 & 45 & 41 & 69 & 55 \\
\hline Prevalence ratios dialysis (pmp) & 446 & 382 & 399 & 437 & 440 \\
\hline Prevalence ratios transplant (pmp) & 497 & 537 & 504 & 540 & 501 \\
\hline Prevalence ratios total (pmp) & 943 & 919 & 903 & 978 & 941 \\
\hline $95 \%$ confidence intervals total (pmp) & $935-951$ & $875-962$ & $878-929$ & $943-1013$ & $933-948$ \\
\hline
\end{tabular}

*Data from the Office for National Statistics, National Records of Scotland and the Northern Ireland Statistics and Research Agency - based on the 2011 census 


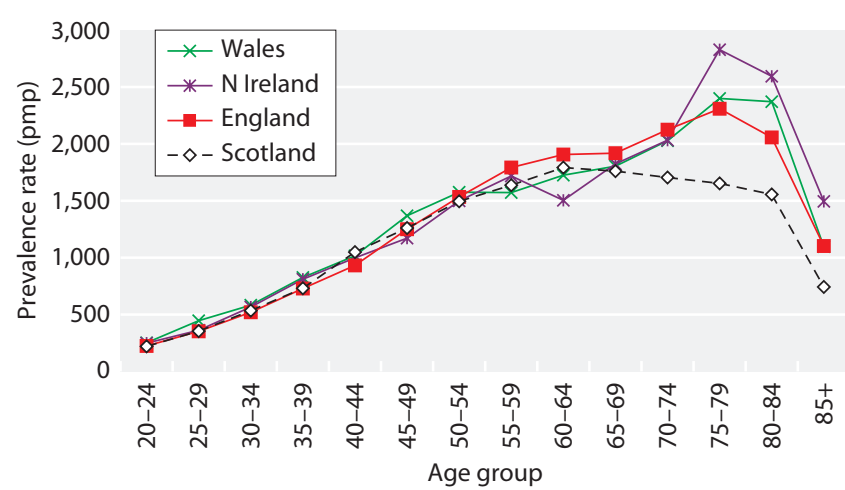

Fig. 2.1. RRT prevalence per million population by age group and UK country on $31 / 12 / 2015$

There were 61,256 adult patients receiving RRT in the UK at the end of 2015, giving an adult UK population prevalence of $941 \mathrm{pmp}$ (table 2.1) compared with $913 \mathrm{pmp}$ in 2014. RRT prevalence increased in all UK countries in 2015. The prevalence of dialysis increased slightly in the UK from $430 \mathrm{pmp}$ in 2014 to $440 \mathrm{pmp}$ in 2015 and there continued to be a slow decline in PD prevalence (55 pmp in 2015 compared with $56 \mathrm{pmp}$ in 2014 and $57 \mathrm{pmp}$ in 2013). This decline in PD prevalence in the UK has been noted since 1997. Conversely, the prevalence of transplanted patients continued to increase in the UK from $482 \mathrm{pmp}$ in 2014 to $501 \mathrm{pmp}$ in 2015. In analyses stratified by country and age group, Northern Ireland exhibited a higher RRT prevalence for patients aged 75 years and older compared with the other UK countries (figure 2.1). In the UK, RRT prevalence in patients aged 80-84 continued to rise from 2,006 per million age related population (pmarp) in 2014 to 2,044 pmarp in 2015 and in patients aged $\geqslant 85$ years from 1,060 pmarp in 2014 to 1,084 pmarp in 2015. This trend has been remarked upon over a number of years and the observed aging of the prevalent population is likely due in part to improving patient survival.

\section{Prevalent patients by RRT modality and centre}

There was a marked variation in the number of prevalent patients across renal centres and the distribution of their treatment modalities varied widely (table 2.2).

\section{Changes in prevalence}

The prevalent UK RRT population grew by $4.3 \%$ between 2014 and 2015 (table 2.3), an annual growth rate which has been fairly consistent over the last 10-15 years (figure 2.2).

The increase in prevalence was smallest in England $(4.0 \%)$ and greatest in Wales (6.4\%). In the case of the latter, this increase was due in part to the way in which Bangor reported transplant patients - previously these were reported by Liverpool Royal with whom Bangor shares the care of its transplant patients. The changes reported here between 2013 and 2014 will differ from those presented in the 18th Annual Report as the current report includes data updates made subsequent to publication of the 18th Annual Report.

The number of prevalent HD patients increased by $2.7 \%$ in 2015 compared with 2014 (table 2.4) which was a greater increase than that seen between 2013 and 2014 (1.3\% growth in prevalence pmp). There continued to be an increase in prevalent transplant patients (3.9\% pmp) and a decrease in prevalent PD patients (1.6\% pmp decrease).

The average annual change in prevalent patients between 2011 and 2015 was a $1.3 \%$ pmp increase in $\mathrm{HD}, 2.1 \%$ pmp fall in $\mathrm{PD}$, and $4.8 \% \mathrm{pmp}$ growth in prevalent transplant patients (table 2.4). In the same period there was an average annual $14.9 \%$ pmp growth in the use of home haemodialysis (data not shown).

The long-term (1998-2015) UK prevalence pattern by treatment modality is shown in figure 2.2. The steady growth in transplant numbers was maintained in 2015. The increase in home haemodialysis patient numbers over this period has been associated with more than a doubling in prevalence, from $2.0 \%$ of the dialysis population in $2005(N=450)$ to $4.2 \%$ in $2015(N=1,175)$. In contrast PD has fallen by $6.2 \%$ between 2005 and 2015 .

Prevalence of RRT in Clinical Commissioning Groups in England (CCGs), Health and Social Care Areas in Northern Ireland (HBs), Local Health Boards in Wales (HBs) and Health Boards in Scotland (HBs)

The need for RRT depends upon many factors such as primary renal diagnosis but also on social and demographic factors such as age, gender, social deprivation and ethnicity. Hence, comparison of crude prevalence ratios by geographical area can be misleading. This section, as in previous reports, uses age and gender standardisation to compare RRT prevalence. The ethnic minority profile is also provided to help understand the differences in standardised prevalence ratios (SPRs).

There were substantial variations in the crude CCG/ HB prevalence ratios pmp, from 631 pmp (NHS Guildford and Waverley, population 206,100) to $1,741 \mathrm{pmp}$ (NHS Brent, population 324,000). There were similar variations in the standardised prevalence ratios (ratio of observed: expected prevalence given the age/gender breakdown of the CCG/HB) from 0.64 (NHS South 
Table 2.2. Number of prevalent RRT patients by treatment modality and centre on $31 / 12 / 2015$

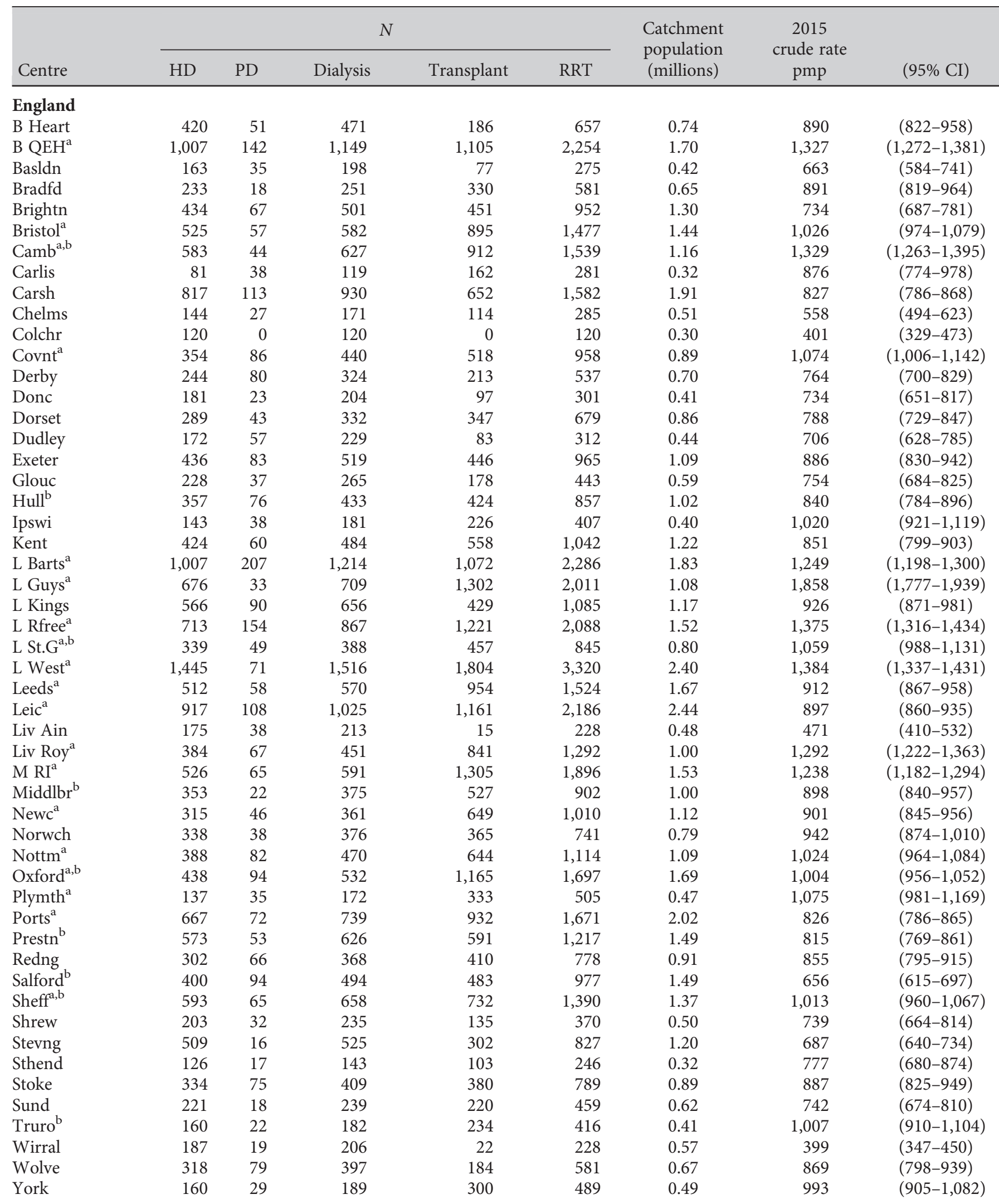


Table 2.2. Continued

\begin{tabular}{|c|c|c|c|c|c|c|c|c|}
\hline \multirow[b]{2}{*}{ Centre } & \multicolumn{5}{|c|}{$N$} & \multirow{2}{*}{$\begin{array}{l}\text { Catchment } \\
\text { population } \\
\text { (millions) }\end{array}$} & \multirow{2}{*}{$\begin{array}{l}2015 \\
\text { crude rate } \\
\text { pmp }\end{array}$} & \multirow[b]{2}{*}{$(95 \% \mathrm{CI})$} \\
\hline & HD & $\mathrm{PD}$ & Dialysis & Transplant & RRT & & & \\
\hline \multicolumn{9}{|c|}{ Northern Ireland } \\
\hline Antrim & 122 & 20 & 142 & 97 & 239 & 0.29 & 811 & $(708-914)$ \\
\hline Belfast $^{\mathrm{a}}$ & 183 & 24 & 207 & 566 & 773 & 0.64 & 1,214 & $(1,128-1,299)$ \\
\hline Newry & 88 & 22 & 110 & 116 & 226 & 0.26 & 865 & $(752-978)$ \\
\hline Ulster & 107 & 6 & 113 & 57 & 170 & 0.27 & 639 & $(543-735)$ \\
\hline West NI & 123 & 12 & 135 & 158 & 293 & 0.35 & 833 & (737-928) \\
\hline \multicolumn{9}{|l|}{ Scotland } \\
\hline Abrdn & 218 & 26 & 244 & 288 & 532 & 0.60 & 887 & $(811-962)$ \\
\hline Airdrie & 195 & 16 & 211 & 214 & 425 & 0.55 & 770 & $(697-843)$ \\
\hline D \& Gall & 54 & 11 & 65 & 65 & 130 & 0.15 & 876 & $(725-1,026)$ \\
\hline Dundee & 187 & 17 & 204 & 217 & 421 & 0.46 & 909 & $(822-996)$ \\
\hline Edinb $^{\mathrm{a}}$ & 284 & 27 & 311 & 462 & 773 & 0.96 & 802 & $(745-858)$ \\
\hline Glasgw $^{\mathrm{a}}$ & 605 & 55 & 660 & 1,055 & 1,715 & 1.62 & 1,056 & $(1,006-1,106)$ \\
\hline Inverns & 93 & 13 & 106 & 147 & 253 & 0.27 & 937 & $(821-1,052)$ \\
\hline Klmarnk & 136 & 37 & 173 & 136 & 309 & 0.36 & 855 & $(760-950)$ \\
\hline Krkcldy & 150 & 20 & 170 & 125 & 295 & 0.32 & 931 & $(825-1,038)$ \\
\hline \multicolumn{9}{|l|}{ Wales } \\
\hline Bangor & 84 & 15 & 99 & 83 & 182 & 0.22 & 834 & $(713-955)$ \\
\hline Cardff ${ }^{\mathrm{a}}$ & 497 & 79 & 576 & 1,037 & 1,613 & 1.42 & 1,136 & $(1,080-1,191)$ \\
\hline Clwyd & 84 & 20 & 104 & 81 & 185 & 0.19 & 975 & $(835-1,116)$ \\
\hline Swanse $^{b}$ & 365 & 62 & 427 & 330 & 757 & 0.89 & 855 & $(794-916)$ \\
\hline Wrexm & 112 & 37 & 149 & 144 & 293 & 0.24 & 1,220 & $(1,080-1,359)$ \\
\hline England & 21,337 & 3,089 & 24,426 & 27,246 & 51,672 & & & \\
\hline N Ireland & 623 & 84 & 707 & 994 & 1,701 & & & \\
\hline Scotland & 1,922 & 222 & 2,144 & 2,709 & 4,853 & & & \\
\hline Wales & 1,142 & 213 & 1,355 & 1,675 & 3,030 & & & \\
\hline UK & 25,024 & 3,608 & 28,632 & 32,624 & 61,256 & & & \\
\hline
\end{tabular}

Centres prefixed 'L' are London centres

The numbers of patients calculated for each country quoted above differ marginally from those quoted elsewhere in this report when patients are allocated to areas by their individual post codes, as some centres treat patients from across national boundaries

${ }^{\text {a Transplant centres }}$

${ }^{\mathrm{b}}$ Subsequent to closing the 2015 database a number of centres reported a variation to the numbers returned. Additionally, this year Cambridge was unable to submit their 2015 data at patient level prior to closing the database and , as such, provided summary numbers of patients still on RRT at the end of 2015 by treatment modality. This centre is therefore excluded from all centre level prevalent analyses. Tables 2.1, 2.3 and 2.4 (but not the remainder of this chapter) reflect these revisions: Hull $(-1)$, Truro $(-1)$, Prestn ( -1$)$, Middlbr $(+9)$, Sheff $(+65)$, L St.G $(-1)$, Oxford $(-1)$, Salford $(+13)$, Camb $(+1,539)$ and Swanse $(+1)$

West Lincolnshire) to 2.17 (Brent) (table 2.5). Confidence intervals are not presented for the crude ratios per million population for 2015 but figures D3 and D4 in appendix D (www.renalreg.org) can be used to determine if a CCG/ $\mathrm{HB}$ falls within the range representing the $95 \%$ confidence limit of the national average prevalence.

Factors associated with variation in standardised prevalence ratios in Clinical Commissioning Groups in England, Health and Social Care Trust Areas in Northern Ireland, Local Health Boards in Wales and Health Boards in Scotland

In 2015, there were 77 CCGs/HBs with a significantly low standardised prevalence ratio (SPR), 110 with a 'normal' SPR and 48 with a significantly high SPR (table 2.5). As has been seen in previous years, they tend to reflect the demographics of the regions in question such that urban, ethnically diverse populations in areas of high social deprivation have the highest prevalence of renal replacement therapy. For example, the association with the level of ethnic diversity is illustrated by the fact that mean SPRs were significantly higher in the $89 \mathrm{CCGs} / \mathrm{HBs}$ with an ethnic minority population $\geqslant 10 \%$ than in those with lower ethnic minority populations $(p<0.001)$. There was a strong, positive correlation between the SPR and percentage of the population that are non-White $(r=0.9 p<0.001)$. In 2015, for each $10 \%$ increase in ethnic minority population, 
Table 2.3. Number of prevalent patients on RRT by centre at year end 2011-2015

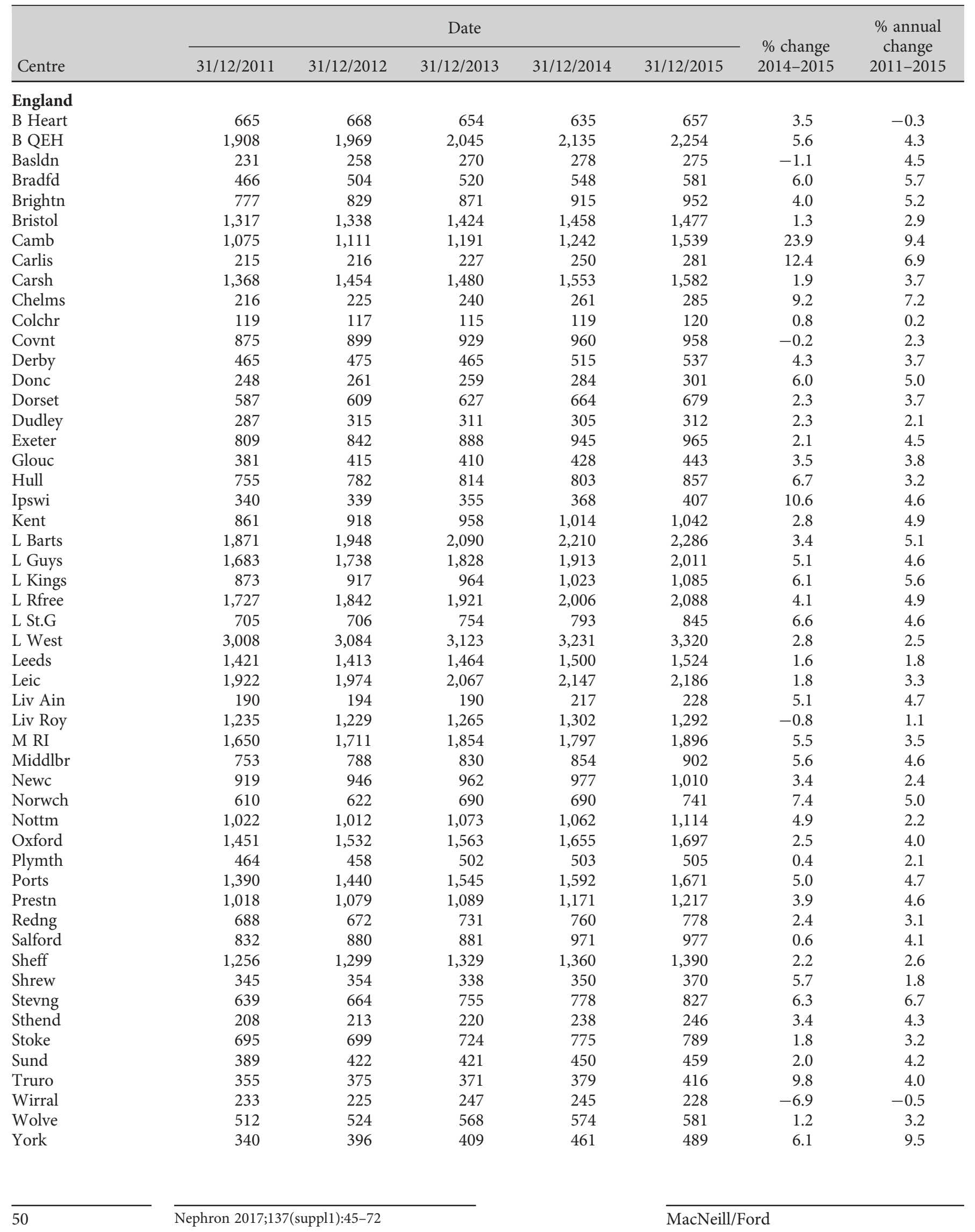


Table 2.3. Continued

\begin{tabular}{|c|c|c|c|c|c|c|c|}
\hline \multirow[b]{2}{*}{ Centre } & \multicolumn{5}{|c|}{ Date } & \multirow{2}{*}{$\begin{array}{l}\% \text { change } \\
2014-2015\end{array}$} & \multirow{2}{*}{$\begin{array}{l}\% \text { annual } \\
\text { change } \\
2011-2015\end{array}$} \\
\hline & $31 / 12 / 2011$ & $31 / 12 / 2012$ & $31 / 12 / 2013$ & $31 / 12 / 2014$ & $31 / 12 / 2015$ & & \\
\hline \multicolumn{8}{|l|}{ N Ireland } \\
\hline Antrim & 225 & 223 & 224 & 229 & 239 & 4.4 & 1.5 \\
\hline Belfast & 683 & 702 & 726 & 747 & 773 & 3.5 & 3.1 \\
\hline Newry & 189 & 188 & 199 & 208 & 226 & 8.7 & 4.6 \\
\hline \multicolumn{8}{|l|}{ Scotland } \\
\hline Abrdn & 480 & 507 & 517 & 502 & 532 & 6.0 & 2.6 \\
\hline Airdrie & 346 & 389 & 389 & 395 & 425 & 7.6 & 5.3 \\
\hline D \& Gall & 124 & 128 & 119 & 130 & 130 & 0.0 & 1.2 \\
\hline Dundee & 397 & 395 & 398 & 401 & 421 & 5.0 & 1.5 \\
\hline Krkcldy & 278 & 278 & 283 & 277 & 295 & 6.5 & 1.5 \\
\hline \multicolumn{8}{|l|}{ Wales } \\
\hline Bangor & 109 & 105 & 99 & 102 & 182 & 78.4 & 13.7 \\
\hline Cardff & 1,531 & 1,544 & 1,582 & 1,591 & 1,613 & 1.4 & 1.3 \\
\hline Clwyd & 137 & 173 & 152 & 166 & 185 & 11.4 & 7.8 \\
\hline Swanse & 659 & 663 & 693 & 707 & 756 & 6.9 & 3.5 \\
\hline Wrexm & 236 & 248 & 251 & 283 & 293 & 3.5 & 5.6 \\
\hline England & 44,369 & 45,900 & 47,821 & 49,664 & 51,672 & 4.0 & 3.9 \\
\hline N Ireland & 1,504 & 1,512 & 1,542 & 1,607 & 1,701 & 5.8 & 3.1 \\
\hline Scotland & 4,320 & 4,474 & 4,541 & 4,583 & 4,853 & 5.9 & 3.0 \\
\hline Wales & 2,672 & 2,733 & 2,777 & 2,849 & 3,030 & 6.4 & 3.2 \\
\hline UK & 52,865 & 54,619 & 56,681 & 58,703 & 61,256 & 4.3 & 3.8 \\
\hline
\end{tabular}

the standardised prevalence ratio increased by 0.17 (equates to $\sim 17 \%$ ). These trends are identical to those identified previously. The relationship between the ethnic composition of a CCG/HB and its SPR is demonstrated in figure 2.3.

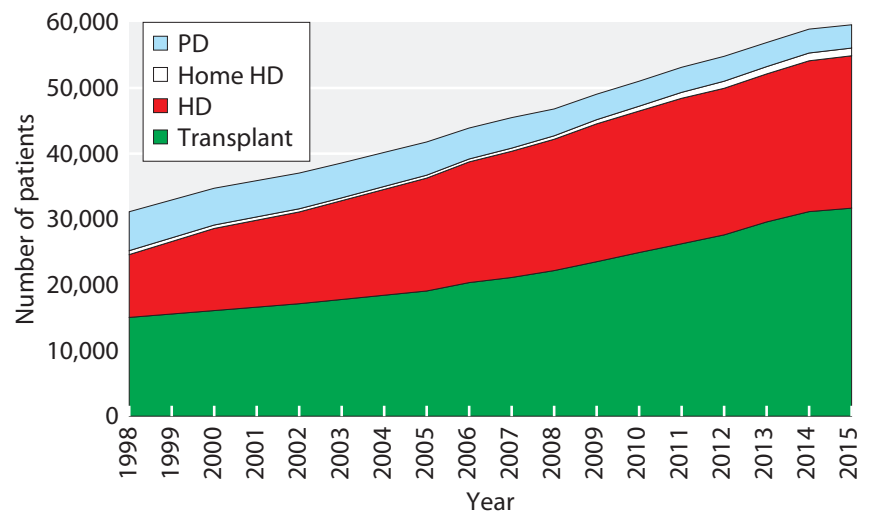

Fig. 2.2. Growth in prevalent patients by treatment modality at the end of each year 1998-2015

UK RRT prevalence in 2015
Only four of the 146 CCGs/HBs with ethnic minority populations of less than $10 \%$ had high SPRs: Abertawe Bro Morgannwg University and Cwm Taf in Wales, Greater Glasgow and Clyde in Scotland, and Belfast in Northern Ireland. Forty-four (49.4\%) of the 89 CCGs/ HBs with ethnic minority populations greater than $10 \%$ had high SPRs, whereas eight (9.0\%) (NHS Chiltern, NHS Brighton and Hove, NHS Richmond, NHS Havering, NHS Solihull, NHS Calderdale, NHS Newcastle and Gateshead, NHS Trafford) had low SPRs. Some of the CCGs/HBs with a high $(>15 \%)$ ethnic minority population had a normal expected RRT prevalence (e.g. NHS Crawley, NHS Kingston, NHS Milton Keynes, NHS Sheffield, NHS South Manchester).

The age and gender standardised prevalence ratios (which do not take into account variation in ethnicity) in each region of England and in Wales, Northern Ireland and Scotland are presented in table 2.6. Wales and Northern Ireland previously had higher than expected RRT prevalence but in more recent years were similar

Nephron 2017;137(suppl1):45-72 
Table 2.4. Change in RRT prevalence ratio pmp 2011-2015 by modality*

\begin{tabular}{|c|c|c|c|c|c|c|c|c|c|c|}
\hline \multirow[b]{2}{*}{ Year } & \multicolumn{5}{|c|}{ Prevalence } & \multicolumn{5}{|c|}{$\%$ growth in prevalence pmp } \\
\hline & HD pmp & $\mathrm{PD}$ pmp & Dialysis pmp & Transplant pmp & RRT pmp & HD & $\mathrm{PD}$ & Dialysis & $\mathrm{Tx}$ & RRT \\
\hline 2012 & 370 & 60 & 430 & 436 & 866 & 1.3 & -0.9 & 1.0 & 5.0 & 3.0 \\
\hline 2013 & 369 & 57 & 427 & 462 & 888 & -0.1 & -4.6 & -0.8 & 5.8 & 2.5 \\
\hline 2014 & 374 & 56 & 430 & 482 & 913 & 1.3 & -1.5 & 0.9 & 4.5 & 2.8 \\
\hline
\end{tabular}

${ }^{*}$ Differences in the figures for dialysis and RRT prevalence and the sum of the separate modalities are due to rounding pmp - per million population

Tx - Transplant

to expected. Scotland had lower than expected RRT prevalence as did the North and South of England. RRT prevalence in London remained higher than expected.

\section{Case mix in prevalent $R R T$ patients}

Time on RRT (vintage)

Table 2.7 shows the median time, in years, since starting RRT of prevalent RRT patients on 31st December 2015. Median time on RRT for all prevalent patients remained fairly static at 6.2 years (6.1 years in 2014). Patients with functioning transplants had survived a median of 10.2 years on RRT whilst the median time on RRT of HD and PD patients was significantly less (3.3 and 1.6 years respectively).

The median time on HD was more than double that on PD and this could reflect early transplantation in the latter as well as higher technique failure rates for PD. Time on transplant is the same as observed in 2013 and 2014, but decreased slightly since 2008 (median 10.4 years) which may reflect a trend towards both the use of more marginal donor kidneys (including Donor after Cardiac Death (DCD) kidneys) and transplantation of older recipients in recent years.

\section{Age}

The median age of prevalent UK patients on RRT at 31st December 2015 (59.0 years, table 2.8) has remained stable over recent years although it is significantly higher than in 2005 when it was 55.0 years. As observed previously, there were marked differences between modalities; the median age of HD patients (67.2 years) was greater than that of those on PD (64.2 years) and substantially higher than that of transplanted patients (53.8 years). Of the UK prevalent RRT population, $50 \%$ were in the 40-64 years age group (table 2.9). The proportion of patients aged 75 years and older varied greatly between countries and was highest in Wales (18.1\%) and Northern Ireland (18.3\%) and lowest in Scotland (12.5\%) (table 2.9). Within countries there were large differences in the proportion of patients aged over 75 (within England these ranged between $9.1 \%$ in Liverpool Royal Infirmary and $46.7 \%$ in Colchester). In most centres the prevalent PD population was younger than the HD population (table 2.8).

Between-centre differences in the median age of prevalent patients by treatment modality can reflect differing demographics of the catchment populations as well as differing approaches to treatment modalities. For example, Colchester had the highest median age (73.1 years), whilst Belfast and London Guy's the lowest (55.0 years each) (table 2.8). This could reflect either variation in the catchment populations or follow-up of younger transplant patients (as noted above in the case of Belfast). The median age of the non-White dialysis population was lower than the overall dialysis population (62.0 vs 67.2 years, data not shown). The differing age distributions of the transplant and dialysis populations are illustrated in figure 2.4, demonstrating that the age peak for prevalent dialysis patients was 24 years later than for prevalent transplant patients.

In the UK on 31 st December 2015, $65.8 \%$ of patients aged less than 65 years on RRT had a functioning transplant (table 2.15), compared with only $31.3 \%$ aged 65 years and over. There was a similar pattern in all four UK countries although the proportion of patients aged less than 65 with a functioning transplant in Northern Ireland $(75.3 \%)$ was much higher than elsewhere.

\section{Gender}

The age distributions of males and females were very similar (data not shown). Standardising the age of the 
Table 2.5. Prevalence of RRT and standardised prevalence ratios in CCG/HB areas

CCG/HB - Clinical Commissioning Groups (England); Health and Social Care Trust Areas (Northern Ireland); Health Boards (Scotland) and Local Health Boards (Wales). Note that 3 CCGs merged in April 2015: Gateshead CCG, Newcastle North \& East CCG and Newcastle West CCG became a single statutory body on 1 April 2015 and are reported here

$\mathrm{O} / \mathrm{E}$ - standardised prevalence ratio. Ratio of observed:expected rate of RRT given the age and gender breakdown of the area

LCL - lower 95\% confidence limit

UCL - upper $95 \%$ confidence limit

pmp - per million population

Areas with significantly low prevalence ratios in 2015 are italicised in greyed areas, those with significantly high prevalence ratios in 2015 are bold in greyed areas

Population numbers are the 2015 mid-year estimates by age group and gender (data obtained from the Office of National Statistics, National Records of Scotland and the Northern Ireland Statistics and Research Agency - based on the 2011 Census)

$\%$ non-White - percentage of the CCG/HB population that is non-White, from 2011 Census

ONS specifies that the populations should be rounded to the nearest 100 when being presented

${ }^{*}$ CCGs where at least $10 \%$ of the RRT population were seen in Cambridge. In these CCGs the rate is underestimated. In the CCGs with $>70 \%$ RRT population covered by Cambridge, the rate for 2015 has been blanked

\begin{tabular}{|c|c|c|c|c|c|c|c|c|c|c|c|c|}
\hline UK area & Name & $\begin{array}{c}\text { Total } \\
\text { population }\end{array}$ & $\begin{array}{c}2010 \\
\mathrm{O} / \mathrm{E} \\
\end{array}$ & $\begin{array}{c}2011 \\
\mathrm{O} / \mathrm{E} \\
\end{array}$ & $\begin{array}{l}2012 \\
\mathrm{O} / \mathrm{E} \\
\end{array}$ & $\begin{array}{l}2013 \\
\mathrm{O} / \mathrm{E} \\
\end{array}$ & $\begin{array}{c}2014 \\
\mathrm{O} / \mathrm{E} \\
\end{array}$ & $\begin{array}{l}2015 \\
\mathrm{O} / \mathrm{E} \\
\end{array}$ & $\begin{array}{l}95 \% \\
\text { LCL } \\
\end{array}$ & $\begin{array}{r}20 \\
95 \% \\
\text { UCL } \\
\end{array}$ & $\begin{array}{l}15 \\
\text { Crude rate } \\
\text { pmp }\end{array}$ & $\begin{array}{c}\% \\
\text { non- } \\
\text { White } \\
\end{array}$ \\
\hline \multirow{6}{*}{$\begin{array}{l}\text { Cheshire, } \\
\text { Warrington } \\
\text { and Wirral }\end{array}$} & NHS Eastern Cheshire & 196,500 & 0.76 & 0.76 & 0.81 & 0.79 & 0.78 & 0.77 & 0.66 & 0.90 & 824 & 3.7 \\
\hline & NHS South Cheshire & 178,900 & 0.92 & 0.89 & 0.86 & 0.88 & 0.92 & 0.93 & 0.80 & 1.09 & 939 & 2.9 \\
\hline & NHS Vale Royal & 102,900 & 0.75 & 0.77 & 0.72 & 0.78 & 0.73 & 0.73 & 0.58 & 0.92 & 729 & 2.1 \\
\hline & NHS Warrington & 207,700 & 0.83 & 0.80 & 0.82 & 0.84 & 0.90 & 0.87 & 0.75 & 1.01 & 838 & 4.1 \\
\hline & NHS West Cheshire & 231,000 & 0.98 & 0.99 & 0.96 & 0.96 & 0.95 & 0.83 & 0.72 & 0.96 & 840 & 2.8 \\
\hline & NHS Wirral & 320,900 & 0.84 & 0.83 & 0.81 & 0.83 & 0.75 & 0.74 & 0.65 & 0.84 & 735 & 3.0 \\
\hline \multirow{5}{*}{$\begin{array}{l}\text { Durham, } \\
\text { Darlington } \\
\text { and Tees }\end{array}$} & NHS Darlington & 105,400 & 0.83 & 0.77 & 0.83 & 0.83 & 0.82 & 0.85 & 0.69 & 1.05 & 835 & 3.8 \\
\hline & NHS Durham Dales, Easington and Sedgefield & 274,000 & 0.94 & 0.98 & 0.94 & 0.98 & 0.97 & 0.98 & 0.87 & 1.11 & 1,000 & 1.2 \\
\hline & NHS Hartlepool and Stockton-on-Tees & 287,300 & 0.86 & 0.89 & 0.93 & 0.90 & 0.93 & 0.88 & 0.78 & 1.00 & 832 & 4.4 \\
\hline & NHS North Durham & 245,700 & 0.77 & 0.76 & 0.83 & 0.79 & 0.78 & 0.77 & 0.67 & 0.89 & 753 & 2.5 \\
\hline & NHS South Tees & 274,800 & 1.06 & 1.09 & 1.08 & 1.09 & 1.05 & 1.10 & 0.98 & 1.24 & 1,041 & 6.7 \\
\hline \multirow{12}{*}{$\begin{array}{l}\text { Greater } \\
\text { Manchester }\end{array}$} & NHS Bolton & 281,600 & 1.06 & 1.10 & 1.10 & 1.07 & 1.02 & 1.05 & 0.93 & 1.18 & 952 & 18.1 \\
\hline & NHS Bury & 187,900 & 0.91 & 0.92 & 0.91 & 0.90 & 0.93 & 0.95 & 0.82 & 1.10 & 889 & 10.8 \\
\hline & NHS Central Manchester & 188,900 & 1.51 & 1.44 & 1.48 & 1.57 & 1.63 & 1.65 & 1.44 & 1.90 & 1,043 & 48.0 \\
\hline & NHS Heywood, Middleton \& Rochdale & 214,200 & 0.95 & 0.99 & 1.00 & 1.03 & 1.03 & 1.03 & 0.89 & 1.18 & 920 & 18.3 \\
\hline & NHS North Manchester & 178,700 & 1.05 & 1.05 & 1.11 & 1.08 & 1.10 & 1.15 & 0.97 & 1.35 & 817 & 30.8 \\
\hline & NHS Oldham & 230,800 & 0.93 & 0.94 & 0.93 & 0.96 & 0.96 & 1.00 & 0.87 & 1.15 & 871 & 22.5 \\
\hline & NHS Salford & 245,600 & 0.85 & 0.84 & 0.87 & 0.89 & 0.87 & 0.83 & 0.71 & 0.96 & 704 & 9.9 \\
\hline & NHS South Manchester & 162,700 & 0.92 & 0.91 & 0.94 & 0.96 & 0.98 & 1.02 & 0.85 & 1.21 & 774 & 19.6 \\
\hline & NHS Stockport & 288,700 & 0.86 & 0.89 & 0.88 & 0.81 & 0.82 & 0.83 & 0.73 & 0.94 & 814 & 7.9 \\
\hline & NHS Tameside and Glossop & 254,900 & 0.94 & 0.93 & 0.93 & 0.92 & 0.90 & 0.90 & 0.78 & 1.02 & 847 & 8.2 \\
\hline & NHS Trafford & 233,300 & 0.88 & 0.85 & 0.85 & 0.87 & 0.88 & 0.84 & 0.73 & 0.97 & 780 & 14.5 \\
\hline & NHS Wigan Borough & 322,000 & 0.82 & 0.89 & 0.93 & 0.95 & 0.96 & 0.90 & 0.80 & 1.01 & 873 & 2.7 \\
\hline \multirow[t]{8}{*}{ Lancashire } & NHS Blackburn with Darwen & 146,800 & 1.23 & 1.28 & 1.26 & 1.25 & 1.23 & 1.25 & 1.07 & 1.47 & 1,062 & 30.8 \\
\hline & NHS Blackpool & 139,600 & 0.81 & 0.80 & 0.91 & 0.99 & 1.08 & 1.07 & 0.91 & 1.25 & 1,060 & 3.3 \\
\hline & NHS Chorley and South Ribble & 172,500 & 0.77 & 0.83 & 0.89 & 0.95 & 0.93 & 0.91 & 0.78 & 1.07 & 893 & 2.9 \\
\hline & NHS East Lancashire & 374,200 & 1.01 & 1.02 & 0.97 & 0.98 & 0.99 & 0.96 & 0.86 & 1.06 & 914 & 11.9 \\
\hline & NHS Fylde \& Wyre & 167,900 & 0.84 & 0.84 & 0.85 & 0.85 & 0.84 & 0.86 & 0.74 & 1.01 & 959 & 2.1 \\
\hline & NHS Greater Preston & 202,800 & 0.87 & 0.83 & 0.89 & 0.87 & 0.88 & 0.89 & 0.76 & 1.03 & 809 & 14.7 \\
\hline & NHS Lancashire North & 161,500 & 0.72 & 0.75 & 0.75 & 0.69 & 0.70 & 0.73 & 0.60 & 0.87 & 700 & 4.0 \\
\hline & NHS West Lancashire & 112,700 & 0.89 & 0.85 & 0.81 & 0.77 & 0.74 & 0.79 & 0.64 & 0.97 & 789 & 1.9 \\
\hline \multirow[t]{6}{*}{ Merseyside } & NHS Halton & 126,500 & 0.96 & 1.06 & 1.02 & 1.00 & 1.00 & 1.02 & 0.85 & 1.21 & 956 & 2.2 \\
\hline & NHS Knowsley & 147,200 & 0.99 & 0.97 & 1.01 & 0.96 & 0.99 & 0.99 & 0.84 & 1.18 & 924 & 2.8 \\
\hline & NHS Liverpool & 478,600 & 1.06 & 1.06 & 1.04 & 1.02 & 1.03 & 1.02 & 0.92 & 1.12 & 871 & 11.1 \\
\hline & NHS South Sefton & 158,600 & 0.88 & 0.95 & 0.95 & 0.94 & 0.98 & 0.97 & 0.83 & 1.14 & 971 & 2.2 \\
\hline & NHS Southport and Formby & 115,100 & 0.78 & 0.82 & 0.75 & 0.79 & 0.80 & 0.79 & 0.64 & 0.96 & 852 & 3.1 \\
\hline & NHS St Helens & 177,600 & 0.92 & 0.90 & 0.91 & 0.87 & 0.86 & 0.85 & 0.72 & 1.00 & 845 & 2.0 \\
\hline
\end{tabular}


Table 2.5. Continued

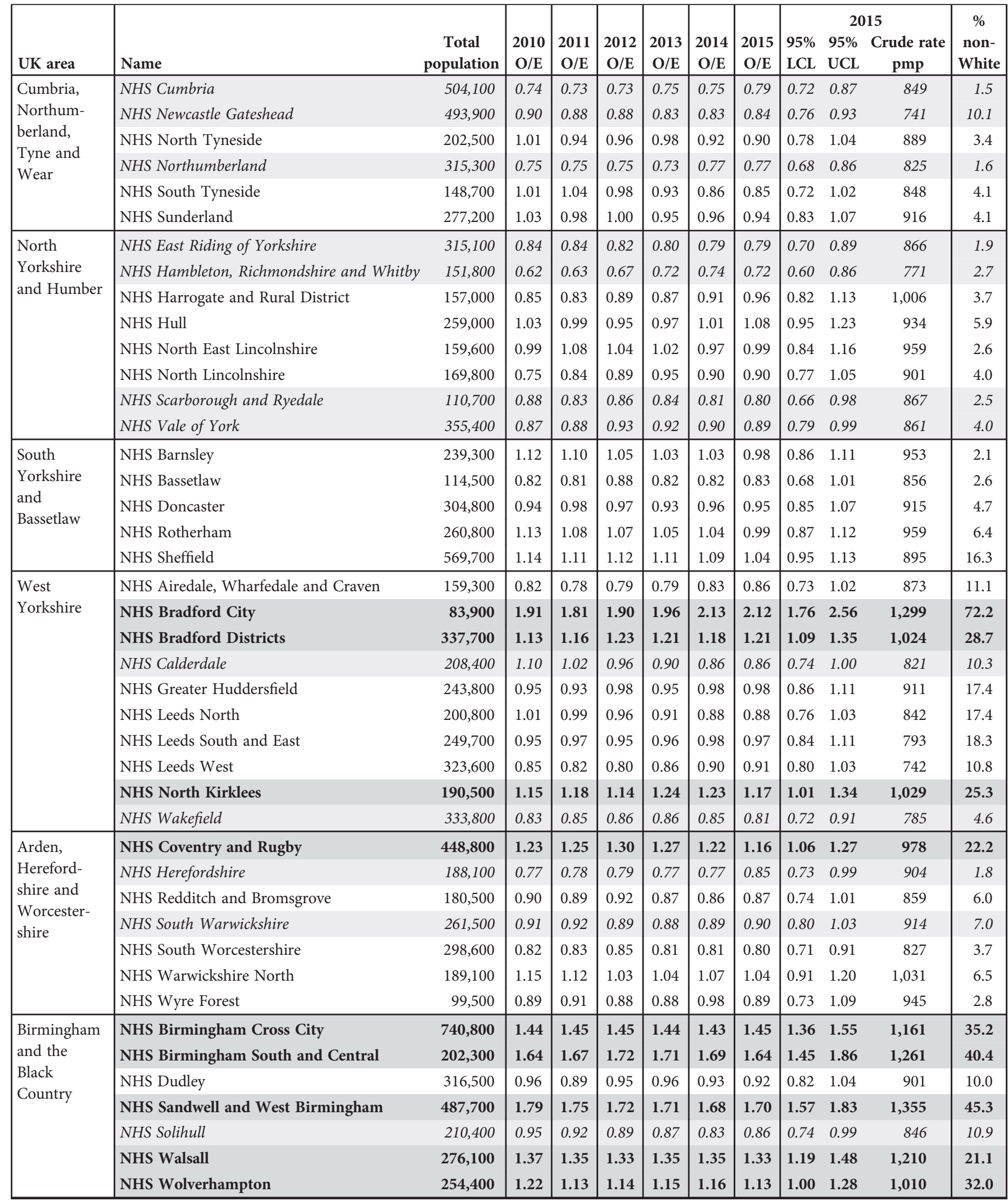


Table 2.5. Continued

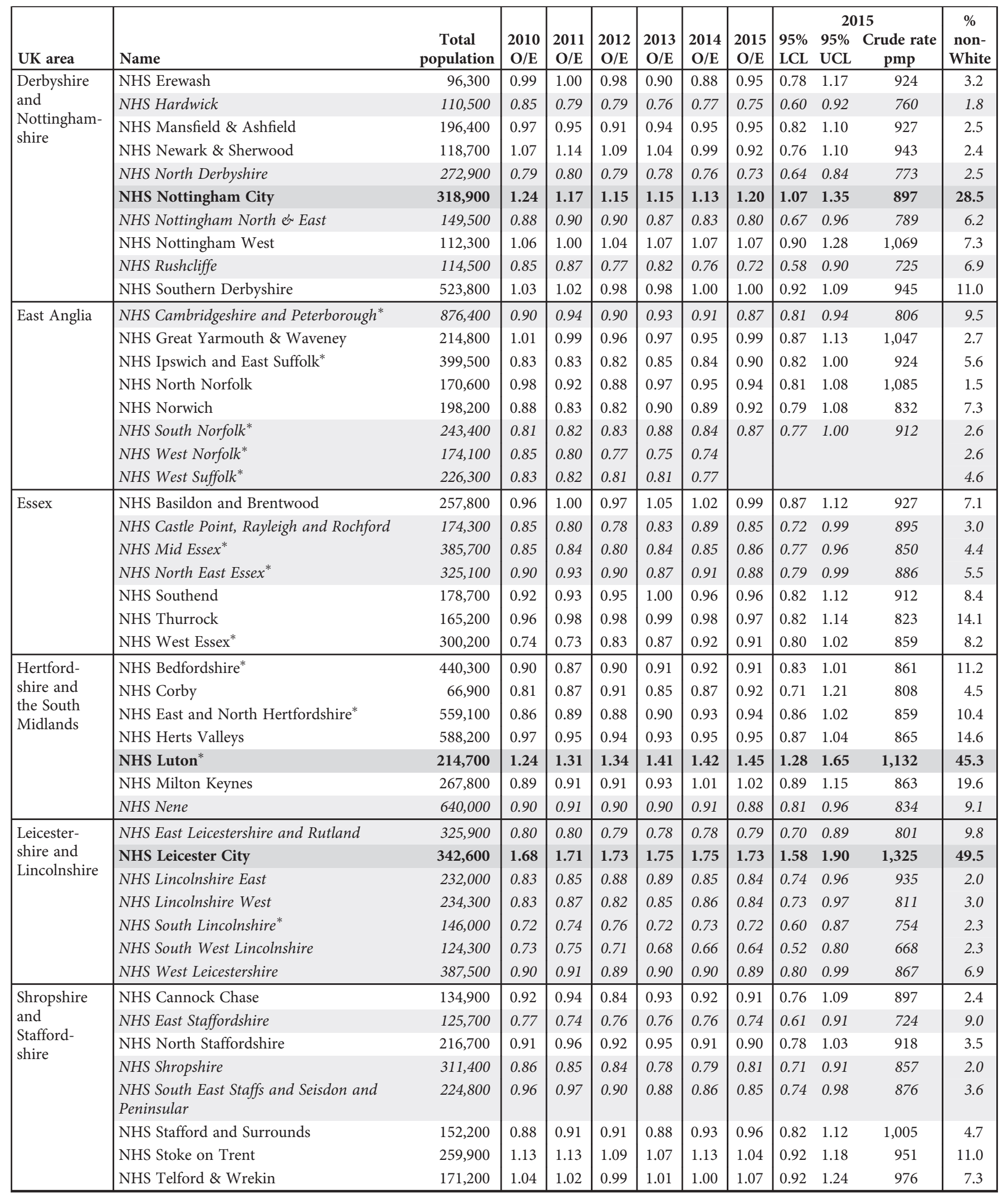


Table 2.5. Continued

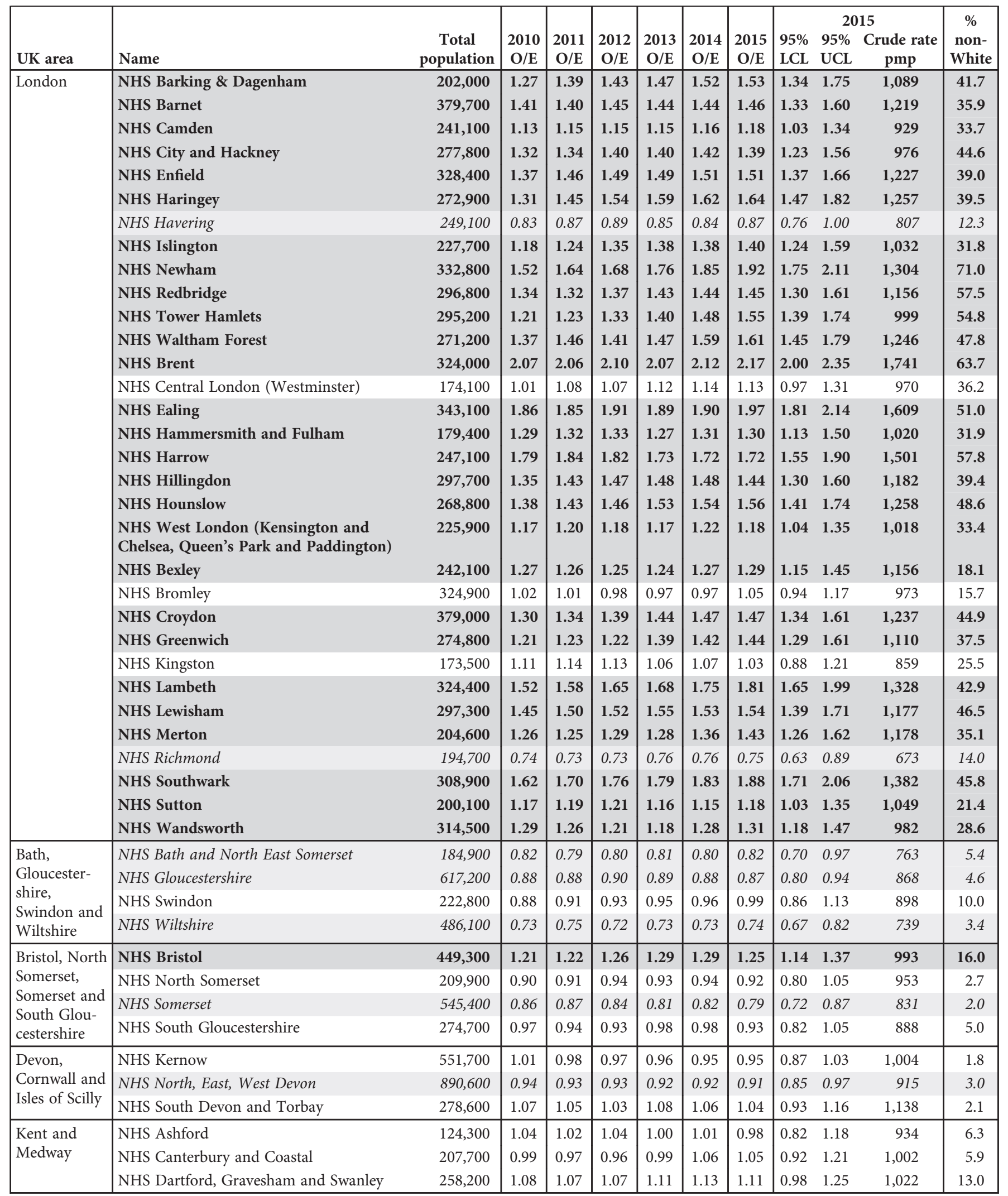


Table 2.5. Continued

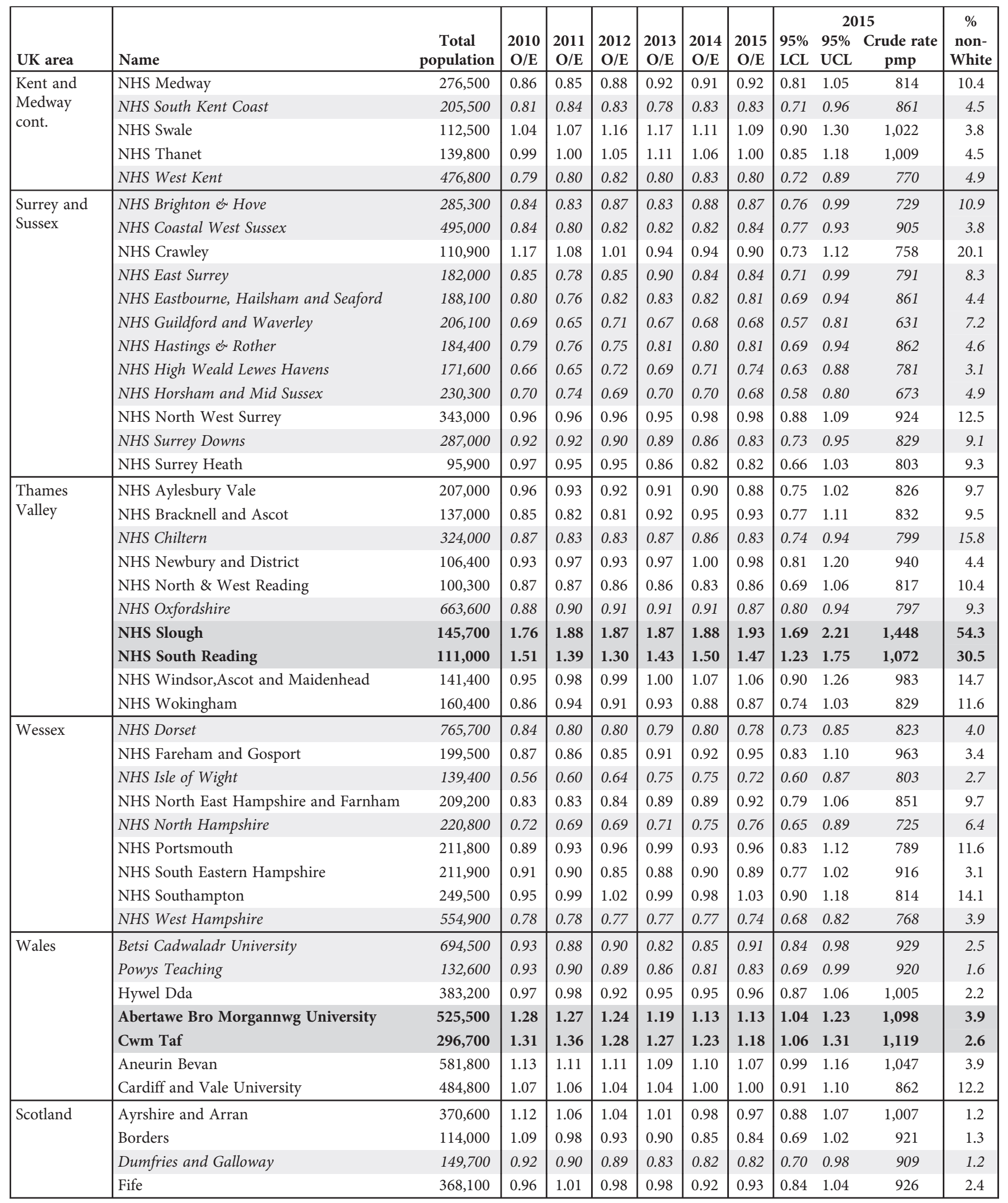


Table 2.5. Continued

\begin{tabular}{|c|c|c|c|c|c|c|c|c|c|c|c|c|}
\hline UK area & Name & $\begin{array}{c}\text { Total } \\
\text { population }\end{array}$ & $\begin{array}{c}2010 \\
\mathrm{O} / \mathrm{E}\end{array}$ & \begin{tabular}{|c|}
2011 \\
$\mathrm{O} / \mathrm{E}$ \\
\end{tabular} & $\begin{array}{c}2012 \\
\mathrm{O} / \mathrm{E} \\
\end{array}$ & $\begin{array}{c}2013 \\
\mathrm{O} / \mathrm{E} \\
\end{array}$ & $\begin{array}{c}2014 \\
\mathrm{O} / \mathrm{E} \\
\end{array}$ & $\begin{array}{c}2015 \\
\mathrm{O} / \mathrm{E}\end{array}$ & \begin{tabular}{|l}
$95 \%$ \\
LCL \\
\end{tabular} & $\begin{array}{r}20 \\
95 \% \\
\text { UCL } \\
\end{array}$ & $\begin{array}{l}15 \\
\text { Crude rate } \\
\text { pmp }\end{array}$ & $\begin{array}{c}\% \\
\text { non- } \\
\text { White }\end{array}$ \\
\hline \multirow[t]{7}{*}{ Scotland cont. } & Forth Valley & 302,700 & 0.96 & 0.90 & 0.87 & 0.87 & 0.86 & 0.87 & 0.77 & 0.98 & 852 & 2.2 \\
\hline & Greater Glasgow and Clyde & $1,149,900$ & 1.07 & 1.06 & 1.08 & 1.07 & 1.04 & 1.06 & 1.00 & 1.13 & 983 & 7.3 \\
\hline & Highland & 321,000 & 0.98 & 0.90 & 0.86 & 0.82 & 0.80 & 0.86 & 0.76 & 0.96 & 907 & 1.3 \\
\hline & Orkney & 21,700 & 0.93 & 0.79 & 0.77 & 0.83 & 0.62 & 0.68 & 0.42 & 1.12 & 738 & 0.7 \\
\hline & Shetland & 23,200 & 0.57 & 0.50 & 0.48 & 0.51 & 0.49 & 0.65 & 0.39 & 1.08 & 647 & 1.5 \\
\hline & Tayside & 415,000 & 1.04 & 1.02 & 0.98 & 0.94 & 0.92 & 0.95 & 0.86 & 1.04 & 942 & 3.2 \\
\hline & Western Isles & 27,100 & 0.85 & 0.70 & 0.60 & 0.58 & 0.73 & 0.90 & 0.62 & 1.32 & 997 & 0.9 \\
\hline \multirow{2}{*}{$\begin{array}{l}\text { Northern } \\
\text { Ireland }\end{array}$} & Belfast & 353,800 & 1.18 & 1.15 & 1.17 & 1.15 & 1.15 & 1.14 & 1.02 & 1.26 & 975 & 3.2 \\
\hline & Western & 299,000 & 1.13 & 1.09 & 1.00 & 0.98 & 1.05 & 1.10 & 0.98 & 1.23 & 963 & 1.0 \\
\hline
\end{tabular}

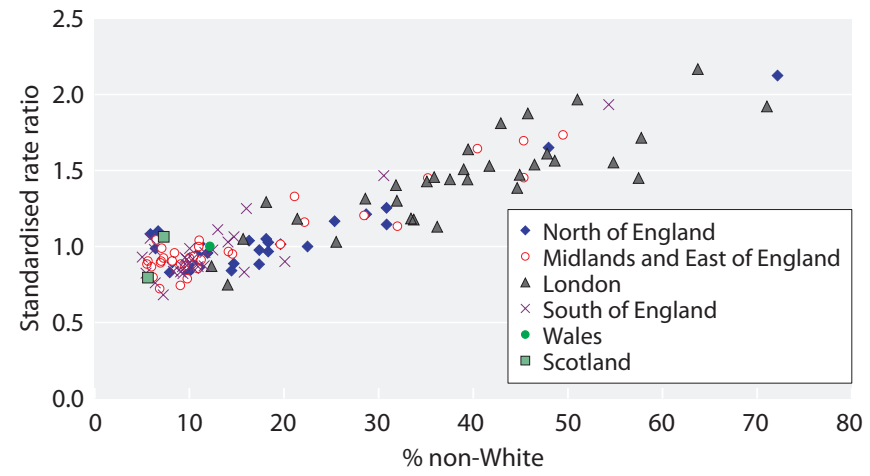

Fig. 2.3. Standardised prevalence ratios for CCG/HB areas by percentage non-White on 31/12/2015 (excluding areas with $<5 \%$ ethnic minorities)
Table 2.7. Median time on RRT of prevalent patients on $31 / 12 / 2015$

\begin{tabular}{lcc}
\hline Modality & $N$ & $\begin{array}{c}\text { Median time treated } \\
\text { (years) }\end{array}$ \\
\hline Haemodialysis & 24,027 & 3.3 \\
Peritoneal dialysis & 3,513 & 1.6 \\
Transplant & 30,392 & 10.2 \\
All RRT & $\mathbf{5 7 , 9 3 2}$ & $\mathbf{6 . 2}$ \\
\hline
\end{tabular}

For patients who recovered for $>90$ days and then subsequently restarted RRT the median time from the start of RRT was calculated from the most recent start date

Patients with an initial treatment modality of transferred in or transferred out were excluded from the calculation of median time on RRT since their treatment start date was not accurately known

Table 2.6. Standardised prevalence rate ratio of RRT for each region in England and for Wales, Scotland and Northern Ireland in 2015

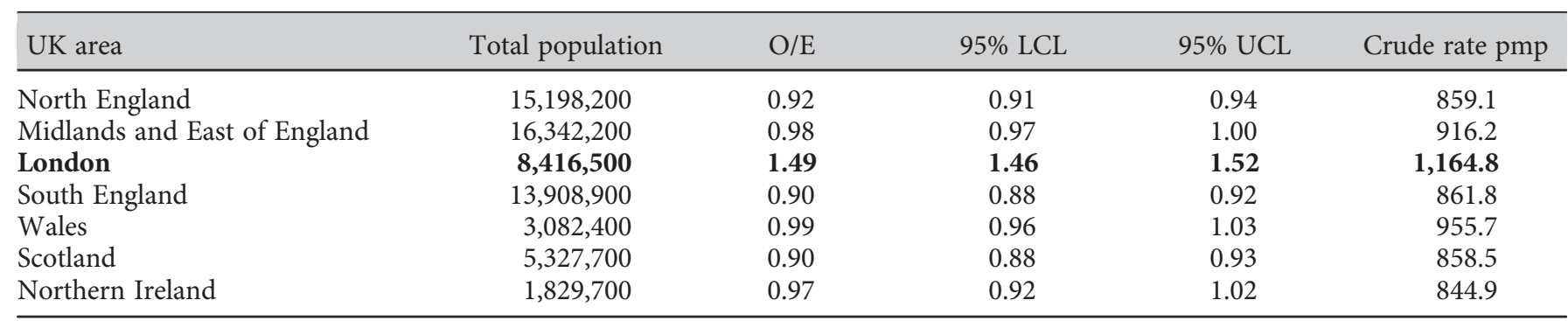

$\mathrm{O} / \mathrm{E}$ - observed/expected prevalence ratio given the age/gender breakdown of each region

Bold - higher than expected prevalence ratio 
Table 2.8. Median age of prevalent RRT patients by treatment modality in renal centres on $31 / 12 / 2015$

\begin{tabular}{|c|c|c|c|c|c|c|c|c|c|}
\hline \multirow[b]{2}{*}{ Centre } & \multicolumn{4}{|c|}{ Median age } & \multirow[b]{2}{*}{ Centre } & \multicolumn{4}{|c|}{ Median age } \\
\hline & $\mathrm{HD}$ & $\mathrm{PD}$ & Transplant & RRT & & HD & $\mathrm{PD}$ & Transplant & RRT \\
\hline B Heart & 68.0 & 67.3 & 52.7 & 64.0 & Salford & 63.3 & 61.7 & 52.5 & 58.1 \\
\hline B QEH & 65.4 & 59.8 & 52.9 & 58.2 & Sheff & 67.0 & 65.5 & 53.3 & 58.9 \\
\hline Basldn & 67.7 & 57.9 & 53.5 & 63.0 & Shrew & 69.0 & 57.7 & 55.8 & 63.7 \\
\hline Bristol & 69.5 & 68.0 & 54.5 & 58.8 & Stoke & 68.0 & 69.0 & 52.4 & 60.1 \\
\hline Carlis & 70.3 & 69.6 & 53.9 & 60.9 & Sund & 65.8 & 64.7 & 55.3 & 59.6 \\
\hline Carsh & 68.9 & 65.6 & 54.8 & 61.9 & Truro & 69.6 & 64.2 & 56.9 & 62.0 \\
\hline Chelms & 69.3 & 70.2 & 58.9 & 64.5 & Wirral & 68.0 & 65.9 & 55.8 & 65.4 \\
\hline Colchr & 73.1 & & & 73.1 & Wolve & 65.9 & 63.4 & 51.8 & 60.6 \\
\hline Covnt & 68.3 & 64.6 & 52.6 & 58.3 & York & 67.7 & 65.4 & 54.0 & 58.8 \\
\hline Exeter & 72.4 & 67.7 & 54.9 & 63.5 & Ulster & 73.8 & 69.5 & 52.7 & 66.5 \\
\hline Glouc & 71.5 & 66.7 & 54.5 & 65.1 & West NI & 71.6 & 61.9 & 50.4 & 57.7 \\
\hline Hull & 68.8 & 65.0 & 53.3 & 59.4 & Scotland & & & & \\
\hline Ipswi & 69.5 & 69.4 & 55.5 & 62.2 & Abrdn & 66.3 & 53.2 & 50.8 & 57.1 \\
\hline Kent & 69.2 & 64.3 & 55.2 & 61.0 & Airdrie & 65.0 & 60.4 & 52.7 & 57.0 \\
\hline L Barts & 61.3 & 60.9 & 51.5 & 56.0 & D \& Gall & 67.0 & 68.6 & 54.1 & 58.9 \\
\hline L Guys & 61.0 & 61.8 & 51.8 & 55.0 & Dundee & 67.8 & 63.9 & 53.5 & 60.7 \\
\hline L Kings & 63.8 & 58.6 & 55.0 & 59.5 & Edinb & 60.1 & 62.8 & 53.5 & 56.0 \\
\hline L Rfree & 69.1 & 63.8 & 53.2 & 58.0 & Glasgw & 65.5 & 62.2 & 53.3 & 57.3 \\
\hline L St.G & 65.9 & 71.2 & 54.5 & 60.5 & Inverns & 66.5 & 59.2 & 51.0 & 56.4 \\
\hline L West & 66.5 & 65.4 & 55.5 & 59.7 & Klmarnk & 64.5 & 61.0 & 54.2 & 58.5 \\
\hline Nottm & 71.3 & 65.0 & 53.2 & 58.5 & England & 67.2 & 64.4 & 53.9 & 59.0 \\
\hline Oxford & 67.8 & 65.6 & 53.4 & 56.5 & N Ireland & 71.0 & 68.7 & 52.1 & 57.8 \\
\hline Plymth & 71.0 & 64.3 & 56.8 & 60.2 & Scotland & 65.4 & 61.1 & 53.2 & 57.5 \\
\hline Ports & 67.5 & 65.1 & 54.6 & 59.5 & Wales & 69.1 & 64.1 & 54.3 & 59.9 \\
\hline Prestn & 66.1 & 67.6 & 54.3 & 60.1 & UK & 67.2 & 64.2 & 53.8 & 59.0 \\
\hline
\end{tabular}

Blank cells indicate no patients on that treatment modality attending that centre when data were collected

UK RRT prevalent patients by using the age and gender distribution of the UK population by CCG/HB (from mid-2015 population estimates), allowed estimation of crude prevalence by age and gender (figure 2.5). This shows a progressive increase in prevalence with age, peaking at 2,270 pmp (similar to the 2,274 pmp estimate in 2014) in the age group 75-79 years then a rapid decline thereafter. Crude RRT prevalence in males exceeded that of females for all age groups. The difference was smallest in younger patients and was greatest from the age of 70 years onwards. RRT prevalence in males was highest in the 75-79 years group $(3,074 \mathrm{pmp})$ and for females also in the same age group at $1,589 \mathrm{pmp}$. Survival on RRT by gender is described in chapter 5 .

\section{Ethnicity}

Key to understanding differences in RRT prevalence between regions is understanding the ethnic diversity of 
Table 2.9. Percentage of prevalent RRT patients in each age group by centre on $31 / 12 / 2015$

\begin{tabular}{|c|c|c|c|c|c|}
\hline \multirow[b]{2}{*}{ Centre } & \multirow[b]{2}{*}{$N$} & \multicolumn{4}{|c|}{ Percentage of patients } \\
\hline & & $18-39$ years & $40-64$ years & $65-74$ years & $75+$ years \\
\hline B Heart & 657 & 10.0 & 42.2 & 22.5 & 25.3 \\
\hline B QEH & 2,254 & 14.3 & 51.2 & 19.3 & 15.3 \\
\hline Basldn & 275 & 10.5 & 45.1 & 21.5 & 22.9 \\
\hline Bristol & 1,477 & 14.7 & 48.1 & 20.7 & 16.5 \\
\hline Carlis & 281 & 12.8 & 47.3 & 19.6 & 20.3 \\
\hline Carsh & 1,582 & 9.4 & 46.3 & 23.3 & 21.0 \\
\hline Chelms & 285 & 9.1 & 43.5 & 24.6 & 22.8 \\
\hline Colchr & 120 & 4.2 & 21.7 & 27.5 & 46.7 \\
\hline Dudley & 312 & 9.0 & 42.9 & 24.0 & 24.0 \\
\hline Exeter & 962 & 10.1 & 42.6 & 24.1 & 23.2 \\
\hline Glouc & 443 & 8.6 & 41.3 & 24.6 & 25.5 \\
\hline Hull & 858 & 13.3 & 48.8 & 21.3 & 16.6 \\
\hline Ipswi & 407 & 9.1 & 47.7 & 23.8 & 19.4 \\
\hline Kent & 1,042 & 11.5 & 47.3 & 23.5 & 17.7 \\
\hline L Barts & 2,286 & 15.6 & 56.9 & 17.1 & 10.4 \\
\hline L Guys & 2,011 & 19.1 & 54.5 & 16.3 & 10.1 \\
\hline L Kings & 1,085 & 9.5 & 53.4 & 18.6 & 18.5 \\
\hline L Rfree & 2,088 & 15.8 & 49.5 & 18.0 & 16.8 \\
\hline L St.G & 846 & 13.4 & 48.2 & 22.9 & 15.5 \\
\hline Norwch & 741 & 10.9 & 46.4 & 22.7 & 20.0 \\
\hline Nottm & 1,114 & 14.4 & 48.7 & 19.8 & 17.1 \\
\hline Oxford & 1,698 & 14.0 & 53.9 & 19.3 & 12.8 \\
\hline Plymth & 505 & 11.7 & 49.5 & 23.0 & 15.8 \\
\hline Ports & 1,671 & 12.6 & 49.7 & 21.5 & 16.3 \\
\hline Prestn & 1,218 & 12.0 & 48.7 & 25.0 & 14.3 \\
\hline Redng & 778 & 8.7 & 48.5 & 23.8 & 19.0 \\
\hline Salford & 964 & 13.7 & 52.7 & 20.7 & 12.9 \\
\hline Sheff & 1,325 & 14.0 & 51.2 & 19.0 & 15.8 \\
\hline Shrew & 370 & 8.9 & 43.8 & 25.1 & 22.2 \\
\hline Stevng & 827 & 10.4 & 46.8 & 19.6 & 23.2 \\
\hline Sthend & 246 & 12.6 & 41.9 & 19.5 & 26.0 \\
\hline Stoke & 789 & 12.8 & 47.4 & 20.3 & 19.5 \\
\hline Sund & 459 & 11.1 & 51.0 & 22.2 & 15.7 \\
\hline Truro & 417 & 10.8 & 45.1 & 23.5 & 20.6 \\
\hline Wirral & 228 & 6.6 & 42.5 & 20.6 & 30.3 \\
\hline Wolve & 581 & 10.7 & 49.7 & 20.1 & 19.4 \\
\hline York & 489 & 15.7 & 47.6 & 20.7 & 16.0 \\
\hline
\end{tabular}


Table 2.9. Continued

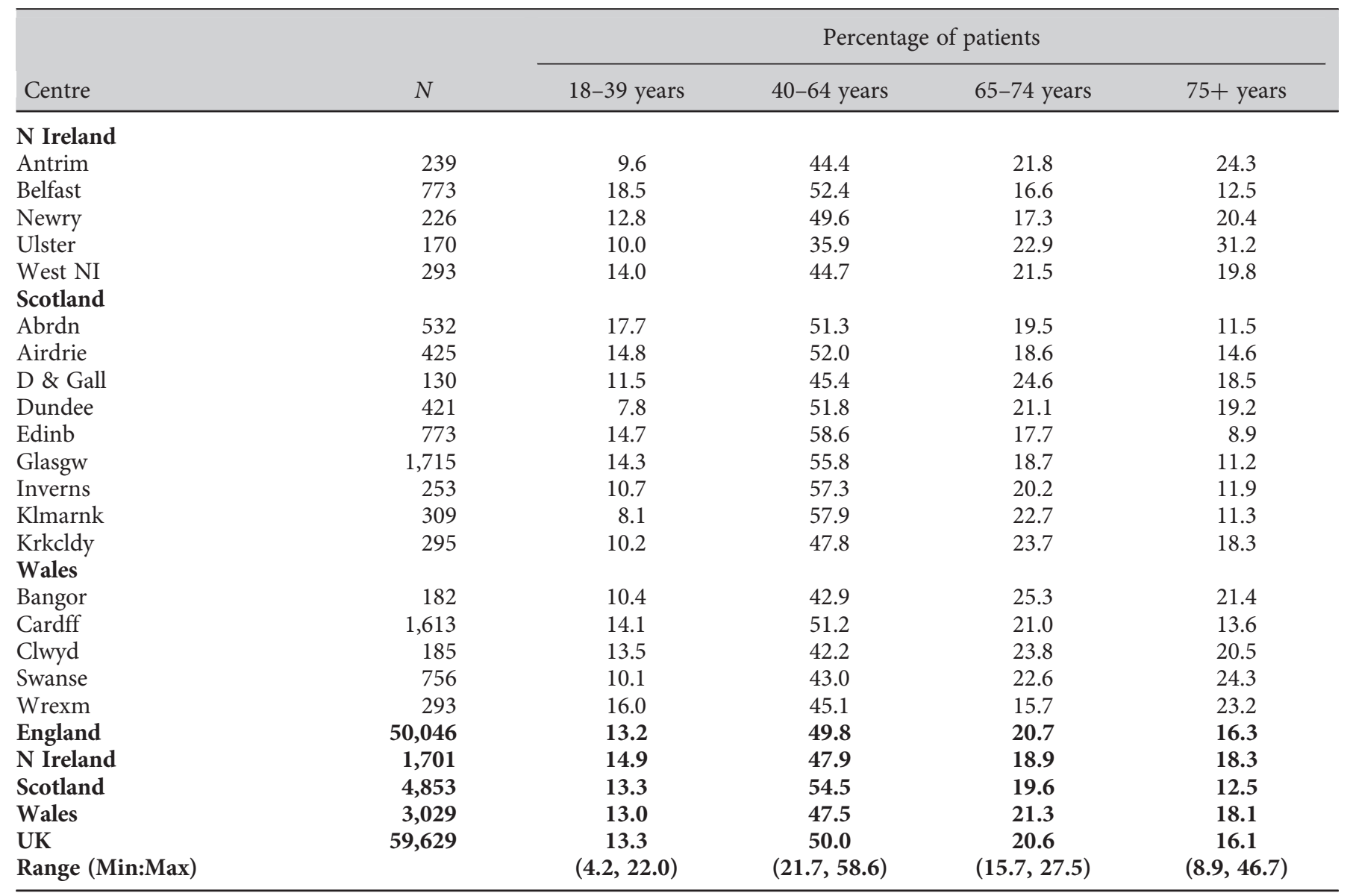

the patient groups. As such, the completeness of ethnicity data provided by renal centres is important. Sixty-one of the 70 centres (87.1\%) providing patient-level data provided ethnicity data that were at least $90 \%$ complete (table 2.10), an improvement on only 36 centres in

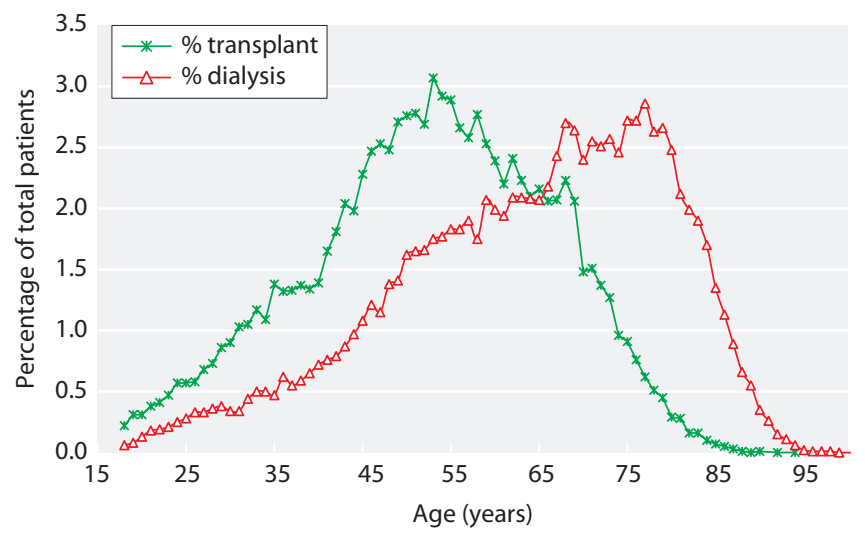

Fig. 2.4. Age profile of prevalent RRT patients by modality on $31 / 12 / 2015$

UK RRT prevalence in 2015
2006. Overall ethnicity completeness for prevalent RRT patients has reached a stable $93.3 \%$ for the UK in 2015 compared to $93.6 \%$ in 2014. Data completeness is very high in England, Wales and Northern Ireland (98.8\%, 99.6\% and 98.6\% respectively), but much lower in Scotland $(30.1 \%)$. Completeness in Scotland is improving,

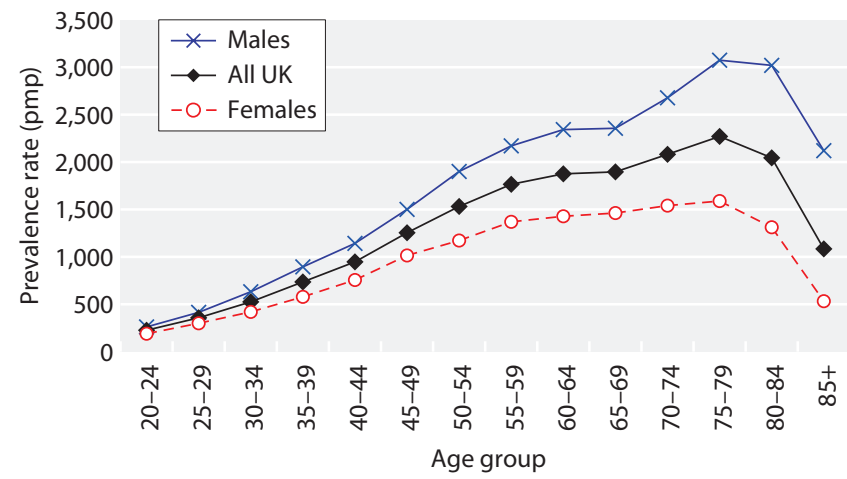

Fig. 2.5. Prevalence of RRT patients per million population by age and gender on $31 / 12 / 2015$

Nephron 2017;137(suppl1):45-72 
Table 2.10. Ethnicity of prevalent RRT patients by centre on $31 / 12 / 2015$

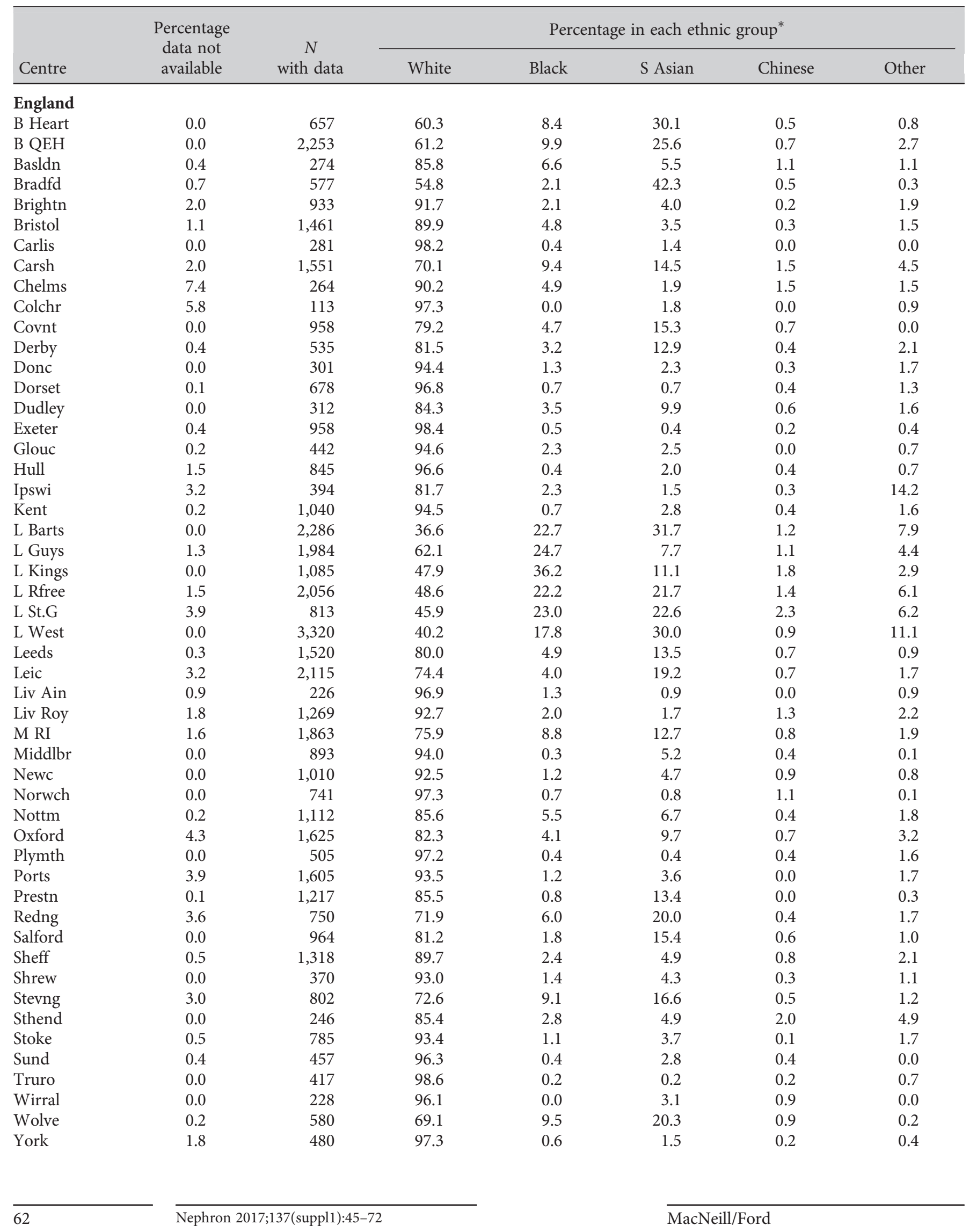


Table 2.10. Continued

\begin{tabular}{|c|c|c|c|c|c|c|c|}
\hline \multirow[b]{2}{*}{ Centre } & \multirow{2}{*}{$\begin{array}{c}\text { Percentage } \\
\text { data not } \\
\text { available }\end{array}$} & \multirow{2}{*}{$\begin{array}{c}N \\
\text { with data }\end{array}$} & \multicolumn{5}{|c|}{ Percentage in each ethnic group* } \\
\hline & & & White & Black & S Asian & Chinese & Other \\
\hline \multicolumn{8}{|l|}{ N Ireland } \\
\hline Antrim & 0.0 & 239 & 99.2 & 0.4 & 0.4 & 0.0 & 0.0 \\
\hline Belfast & 3.1 & 749 & 97.9 & 0.4 & 1.3 & 0.3 & 0.1 \\
\hline Newry & 0.0 & 226 & 99.6 & 0.0 & 0.0 & 0.4 & 0.0 \\
\hline \multicolumn{8}{|l|}{ Scotland } \\
\hline Abrdn & 63.2 & 196 & & & & & \\
\hline Airdrie & 43.1 & 242 & 98.3 & 0.8 & 0.8 & 0.0 & 0.0 \\
\hline D \& Gall & 78.5 & 28 & & & & & \\
\hline Dundee & 60.6 & 166 & & & & & \\
\hline Edinb & 79.8 & 156 & & & & & \\
\hline \multicolumn{8}{|l|}{ Wales } \\
\hline Bangor & 0.0 & 182 & 97.8 & 0.0 & 0.5 & 0.0 & 1.6 \\
\hline Cardff & 0.7 & 1,601 & 92.8 & 1.1 & 4.7 & 0.7 & 0.7 \\
\hline Clwyd & 0.0 & 185 & 97.3 & 0.5 & 2.2 & 0.0 & 0.0 \\
\hline Swanse & 0.0 & 756 & 97.2 & 0.4 & 2.0 & 0.0 & 0.4 \\
\hline Wrexm & 0.0 & 293 & 98.0 & 0.7 & 0.3 & 0.7 & 0.3 \\
\hline England & 1.2 & 49,469 & 75.0 & 8.3 & 13.0 & 0.7 & 3.0 \\
\hline N Ireland & 1.4 & 1,677 & 98.3 & 0.5 & 0.8 & 0.4 & 0.1 \\
\hline Scotland & 69.9 & 1,459 & 95.8 & 1.0 & 1.9 & 0.4 & 0.8 \\
\hline Wales & 0.4 & 3,017 & 95.0 & 0.8 & 3.2 & 0.4 & 0.6 \\
\hline UK & 6.7 & 55,622 & 77.3 & 7.4 & 11.8 & 0.7 & 2.7 \\
\hline
\end{tabular}

Percentage breakdown is not shown for centres with less than $50 \%$ data completeness, but these centres are included in national averages

* See appendix $\mathrm{H}$ for ethnicity coding

however, and only two years ago was $23.0 \%$. Here, completeness of ethnicity data was highest in prevalent transplant patients (39.0\%) which likely reflects improved data recording during the intensive work-up for transplantation.

In $2015,22.7 \%$ of the prevalent UK RRT population (with ethnicity assigned) were from ethnic minorities (25.0\% in England). The proportion of the prevalent UK RRT population (with ethnicity assigned) from ethnic minorities in Wales, Scotland and Northern Ireland was very small, although it should be noted that there was a high level of missing ethnicity data in Scotland as described above. The ONS estimates that approximately $14 \%$ of the UK general population is designated as belonging to an ethnic minority [1]. The relative proportion of patients reported to the UKRR as receiving RRT and belonging to an ethnic minority has increased from $14.9 \%$ in 2007 to $22.7 \%$ in 2015 which may reflect improvements in coding and reporting of ethnicity data as well as an increasing incidence of ERF and increased referral rates in these populations.

Amongst the centres with more than 50\% returns there was wide variation in the proportion of patients from ethnic minorities, ranging from $0.4 \%$ in Newry to 63.4\% in London St Bartholomew's.

\section{Primary renal diagnosis}

Primary renal diagnosis (PRD) is associated with patient outcomes and as it could be used for case-mix adjustment, high levels of data completeness is important. Data for PRD were not complete for $2.6 \%$ of patients (table 2.11), but there exists a marked inter-centre difference in completeness of data returns. One centre had $\geqslant 40 \%$ primary renal diagnosis data coded as uncertain and has been excluded from the between centre analysis and other analyses where PRD is included in the casemix adjustment (Colchester, 47\% uncertain PRD); the UK and national totals have been appropriately adjusted. 
Table 2.11. Primary renal diagnosis in prevalent RRT patients by age and gender on $31 / 12 / 2015$

\begin{tabular}{|c|c|c|c|c|c|c|c|c|}
\hline \multirow[b]{2}{*}{ Primary diagnosis* } & \multirow[b]{2}{*}{$N$} & \multirow{2}{*}{$\begin{array}{c}\% \text { all } \\
\text { patients }\end{array}$} & \multirow{2}{*}{$\begin{array}{c}\text { Intercentre } \\
\text { range } \%\end{array}$} & \multicolumn{2}{|c|}{ Age $<65$} & \multicolumn{2}{|c|}{ Age $\geqslant 65$} & \multirow{2}{*}{$\begin{array}{l}\mathrm{M}: \mathrm{F} \\
\text { ratio }\end{array}$} \\
\hline & & & & $N$ & $\%$ & $N$ & $\%$ & \\
\hline Aetiology uncertain & 9,168 & 15.5 & $4.4-31.2$ & 5,226 & 13.9 & 3,942 & 18.1 & 1.5 \\
\hline Glomerulonephritis & 11,391 & 19.1 & $8.3-26.9$ & 8,140 & 21.6 & 3,251 & 14.9 & 2.1 \\
\hline Pyelonephritis & 6,289 & 10.6 & $5.2-18.6$ & 4,593 & 12.2 & 1,696 & 7.8 & 1.1 \\
\hline Diabetes & 9,913 & 16.7 & $8.9-27.7$ & 5,830 & 15.5 & 4,083 & 18.7 & 1.6 \\
\hline Polycystic kidney & 5,980 & 10.0 & $4.0-16.4$ & 3,856 & 10.2 & 2,124 & 9.7 & 1.1 \\
\hline Hypertension & 3,707 & 6.2 & $1.7-17.2$ & 2,001 & 5.3 & 1,706 & 7.8 & 2.4 \\
\hline Renal vascular disease & 1,760 & 3.0 & $0.5-9.7$ & 376 & 1.0 & 1,384 & 6.3 & 2.0 \\
\hline Other & 9,758 & 16.4 & $11.2-30.5$ & 6,818 & 18.1 & 2,940 & 13.5 & 1.3 \\
\hline Not sent & 1,542 & 2.6 & $0.0-24.3$ & 864 & 2.3 & 678 & 3.1 & 1.6 \\
\hline
\end{tabular}

* See appendix H: ERA-EDTA coding

Excluded centre: $\geqslant 40 \%$ primary renal diagnosis aetiology uncertain (Colchr)

The percentage of patients with uncertain aetiology for the remaining 69 centres providing individual-level data ranged between $4.4 \%$ and $31.2 \%$, which is comparable to recent years. No centre had $>30 \%$ missing data in 2015 and overall rates of incomplete data are improving.

As observed in previous years, glomerulonephritis (GN) was the most common primary renal diagnosis in the 2015 prevalent cohort at $19.1 \%$ (table 2.11). Diabetic nephropathy accounted for $16.7 \%$ of renal disease in prevalent patients on RRT, although it was more common in the 65 and over year age group compared to the younger group ( $18.7 \%$ vs $15.5 \%)$. This contrasted with incident patients where diabetic nephropathy was the predominant diagnostic code in $27.5 \%$ of new RRT patients. The frequency of individual primary renal diagnoses varied with age; patients aged under 65 years and younger were more likely to have GN $(21.5 \%)$ or diabetes (15.5\%) and less likely to have renal vascular disease $(1.0 \%)$ as the cause of their renal failure. This contrasts with older patients ( $\geqslant 65$ years) among whom $6.3 \%$ have renal vascular disease as the cause of their renal failure. Uncertain aetiology was a more common cause in this age group than amongst younger patients $(18.1 \%$ compared with $13.9 \%$ amongst patients $<65$ years).

As described in previous years, the male: female ratio was greater than $1: 1$ for all primary renal diagnoses (table 2.11). The biggest differences between males and females were for GN (male: female ratio of 2.1), hypertension (2.4) and renal vascular disease (2.0).

Trends in the transplant: dialysis ratio by primary diagnosis differed markedly between older and younger patients. In individuals aged less than 65 years, the renal transplantation to dialysis ratio was greater than 1 in all PRD groups except diabetic nephropathy and renal vascular disease. In those aged $\geqslant 65$ years, dialysis was more prevalent than renal transplantation in all PRD groups except polycystic kidney disease (PKD) (table 2.12).

\section{Diabetes}

Throughout this section the term 'diabetic nephropathy' is used to denote patients in whom diabetes mellitus is considered to be the primary cause of the kidney disease rather than merely an associated comorbidity. It includes all prevalent patients with type 1 or type 2 diabetes as the primary renal diagnosis (ERA-EDTA coding). This analysis did not differentiate between type 1 and type 2 diabetes as this distinction was not made in the data submitted by most centres.

The number of prevalent patients with diabetic nephropathy has increased steadily over the last number

Table 2.12. Transplant: dialysis ratios by age and primary renal disease in the prevalent RRT population on 31/12/2015

\begin{tabular}{lcc}
\hline & \multicolumn{2}{c}{ Transplant: dialysis ratio } \\
\cline { 2 - 3 } Primary diagnosis $^{*}$ & $<65$ & $\geqslant 65$ \\
\hline Aetiology uncertain & 2.1 & 0.4 \\
Glomerulonephritis & 2.4 & 0.9 \\
Pyelonephritis & 2.9 & 0.6 \\
Diabetes & 0.9 & 0.2 \\
Polycystic kidney & 3.1 & 1.8 \\
Hypertension & 1.4 & 0.4 \\
Renal vascular disease & 0.9 & 0.1 \\
Other & 2.1 & 0.4 \\
Not sent & 0.8 & 0.1 \\
\hline
\end{tabular}

*appendix H ERA-EDTA coding

Excluded centre: $\geqslant 40 \%$ primary renal diagnosis aetiology uncertain (Colchr) 
Table 2.13. Age relationships in patients with diabetes and patients without diabetes and modality in prevalent RRT patients on $31 / 12 / 2015$

\begin{tabular}{lcc}
\hline & $\begin{array}{c}\text { Patients with } \\
\text { diabetes }^{\mathrm{a}}\end{array}$ & $\begin{array}{c}\text { Patients without } \\
\text { diabetes }^{\mathrm{b}}\end{array}$ \\
\hline$N$ & 9,913 & 48,054 \\
M : F ratio & 1.63 & 1.54 \\
Median age on 31/12/15 & 62 & 58 \\
Median age at start of RRT R d $^{\mathrm{d}}$ & 56 & 48 \\
Median years on RRT & 3.6 & 7.3 \\
\% HD & 58 & 37 \\
\% PD & 8 & 5 \\
\% transplant & 34 & 58 \\
\hline
\end{tabular}

Excluded centre: $\geqslant 40 \%$ primary renal diagnosis aetiology uncertain (Colchr)

${ }^{\text {a }}$ Patients with diabetes: patients with a primary renal disease code of diabetes

${ }^{b}$ Patients without diabetes: all patients excluding patients with diabetes as a PRD and patients with a missing primary renal disease code

${ }^{c}$ Median age at start of RRT was calculated from the most recent RRT start date

${ }^{\mathrm{d}}$ Patients with an initial treatment modality of transferred in or transferred out were excluded from the calculation of median age at start of RRT and median years on RRT, since their treatment start date was not accurately known

of years and grew by $4.8 \%$ to 9,913 in 2015 , from 9,456 in 2014 , representing $17.1 \%$ of all prevalent patients (compared with $13.5 \%$ in 2006) (table 2.13). The male: female ratio for diabetic nephropathy was 1.6. The median age at start of RRT for patients with diabetic nephropathy (56 years) was eight years higher than those with other PRDs (48 years), although the median age at the end of 2015 for prevalent patients with diabetic nephropathy was only four years higher than for individuals without diabetic nephropathy. This reflects reduced survival for patients with diabetes compared with patients without diabetes on RRT. This is also supported by the lower median time on RRT for patients with diabetic nephropathy (3.6 years vs 7.3 years for those without diabetic nephropathy) and this difference in survival has not changed over the last five years (3.4 years vs 6.5 years in 2010). The age at starting RRT in those with diabetic nephropathy was four years younger in Scotland compared with the UK average (data not shown).

There were large differences in the distribution of treatment modalities in those with diabetic nephropathy compared with those without. Fifty eight percent of patients with diabetic nephropathy were undergoing HD compared with just $37 \%$ of patients with any other primary renal diagnosis (table 2.13). The percentage of patients with a functioning transplant was much lower
Table 2.14. Treatment modalities by age and diabetes status on $31 / 12 / 2015$

\begin{tabular}{lccccc}
\hline & \multicolumn{2}{c}{$<65$} & & 2 \\
\cline { 2 - 3 } \cline { 5 - 6 } & Diabetes $^{\mathrm{a}}$ & $\begin{array}{c}\text { All other } \\
\text { causes }^{\mathrm{b}}\end{array}$ & & Diabetes $^{\mathrm{a}}$ & $\begin{array}{c}\text { All other } \\
\text { causes }^{\mathrm{b}}\end{array}$ \\
\hline$N$ & 5,830 & 31,011 & & 4,083 & 17,043 \\
$\% \mathrm{HD}$ & 44.7 & 25.8 & & 77.7 & 56.0 \\
\% PD & 7.3 & 4.3 & & 8.3 & 7.6 \\
\% transplant & 48.1 & 69.9 & & 14.0 & 36.4 \\
\hline
\end{tabular}

Excluded centre: $\geqslant 40 \%$ PRD aetiology uncertain (Colchr)

${ }^{a}$ Patients with diabetes: patients with a primary renal disease code of diabetes

${ }^{b}$ Patients without diabetes: calculated as all patients excluding patients with diabetes as a PRD and patients with a missing primary renal disease code

in prevalent patients with diabetic nephropathy than in prevalent patients without ( $34 \%$ vs $58 \%$ ). However, the proportion of patients with diabetic nephropathy with a functioning transplant has increased since 2005 when only $26.9 \%$ of patients with diabetic nephropathy had a functioning transplant. For older patients with diabetic nephropathy (age $\geqslant 65$ years), only $14.0 \%$ had a functioning transplant compared with $48.1 \%$ of their peers with other primary diagnoses (table 2.14). In the UK, $34.0 \%$ of prevalent patients with diabetic nephropathy had a functioning transplant compared with the UK average of $58.0 \%$ amongst those with other primary diagnoses. Amongst those patients receiving dialysis, a higher proportion of prevalent patients without diabetic nephropathy $(18.0 \%)$ were on home dialysis therapies (home $\mathrm{HD}$ and PD) compared with prevalent patients with diabetic nephropathy (13.8\%).

\section{Modalities of treatment}

Transplantation was the most common treatment modality (53.1\%) for prevalent RRT patients in 2015, followed closely by centre-based HD (39.0\%) in either hospital centre (17.8\%) or satellite unit (21.2\%) (figure 2.6). Satellite HD was again more prevalent than in-centre HD, a trend first noted in 2012. Home therapies made up the remaining $7.9 \%$ of treatment therapies, largely $\mathrm{PD}$ in its different formats (5.9\%) which followed a similar pattern since 2012. The proportion on continuous ambulatory peritoneal dialysis (CAPD) and automated PD (APD) was $2.5 \%$ and $3.4 \%$ respectively, although the proportion on APD may be an underestimate due to centre level coding issues which meant the UKRR could not always distinguish between these therapies. 


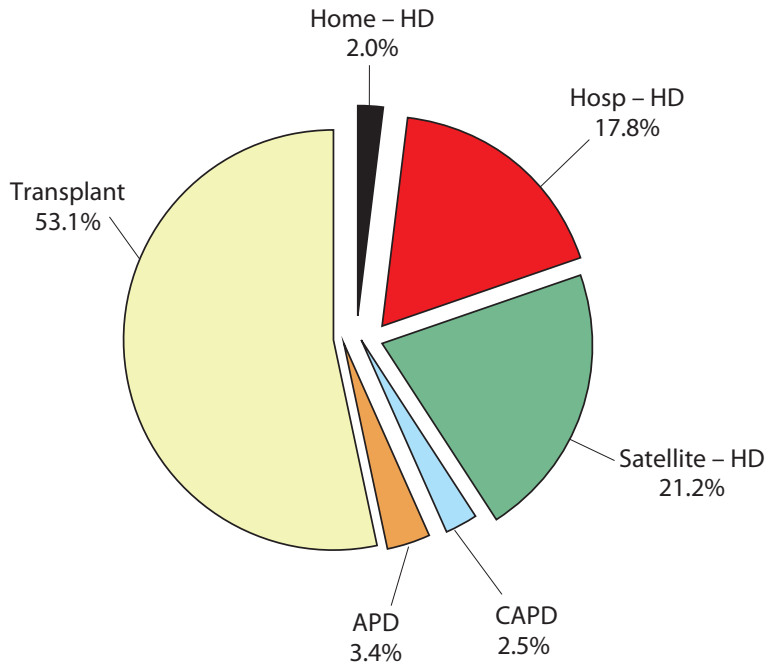

Fig. 2.6. Treatment modality in prevalent RRT patients on $31 / 12 / 2015$

As described earlier, treatment modality was related to patient age. Younger patients (age $<65$ years), were more likely to have a functioning transplant $(65.8 \%)$ when compared with patients aged 65 and over (31.3\%) (table 2.15). HD was the principal modality in the older patient group (60.9\%).
Figure 2.7 shows the distribution of RRT modalities by age group. From the age of 45 years onwards, transplant prevalence declined as HD prevalence increased. The proportion of each age group treated by PD remained relatively stable.

As the HD prevalence varied by age group, the proportion of prevalent dialysis patients receiving $\mathrm{HD}$ varied between centres ranging from $68.1 \%$ in Carlisle to $100 \%$ in Colchester (table 2.16).

Of the dialysis population, $45.2 \%$ received their treatment at a satellite haemodialysis unit in 2015. This figure remains comparable to recent years, but represents an increase from $39.9 \%$ in 2010 . In 2015, the number of centres that had more than $50 \%$ of their haemodialysis activity taking place in satellite units was 27 (figure 2.8). Although there are satellite units in Scotland, the data provided for 2015 did not distinguish between main centre and satellite unit haemodialysis. As such, it is difficult to accurately assess access to satellite haemodialysis across the UK as a whole, so the statistics pool only England, Wales and Northern Ireland data.

There was also wide variation between centres in the proportion of dialysis patients being managed with APD, ranging from $0.0 \%$ to $24.2 \%$ (table 2.16 ). While

Table 2.15. Percentage of prevalent RRT patients by dialysis and transplant modality by UK country on $31 / 12 / 2015$

\begin{tabular}{|c|c|c|c|c|c|c|c|c|}
\hline \multirow[b]{2}{*}{ UK country } & \multicolumn{4}{|c|}{$<65$ years } & \multicolumn{4}{|c|}{$\geqslant 65$ years } \\
\hline & $N$ & $\% \mathrm{HD}$ & $\% \mathrm{PD}$ & $\%$ transplant & $N$ & $\% \mathrm{HD}$ & $\% \mathrm{PD}$ & $\%$ transplant \\
\hline England & 31,541 & 29.8 & 4.9 & 65.2 & 18,505 & 61.0 & 8.0 & 31.0 \\
\hline N Ireland & 1,068 & 21.2 & 3.6 & 75.3 & 633 & 62.7 & 7.3 & 30.0 \\
\hline Scotland & 3,293 & 28.6 & 4.1 & 67.3 & 1,560 & 62.8 & 5.6 & 31.6 \\
\hline Wales & 1,834 & 25.5 & 6.2 & 68.3 & 1,195 & 56.4 & 8.4 & 35.2 \\
\hline UK & 37,736 & 29.3 & 4.9 & 65.8 & 21,893 & 60.9 & 7.8 & 31.3 \\
\hline
\end{tabular}
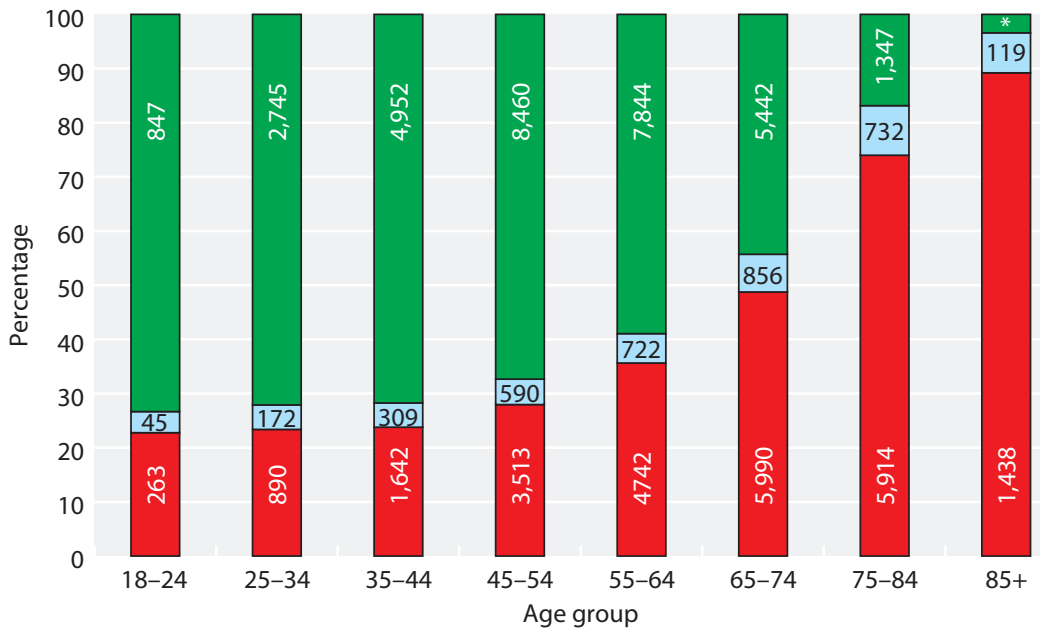

Fig. 2.7. Treatment modality distribution by age in prevalent RRT patients on $31 / 12 / 2015$ ${ }^{*} N=55$ 
Table 2.16. Percentage of prevalent dialysis patients by dialysis modality and centre on $31 / 12 / 2015$

\begin{tabular}{|c|c|c|c|c|c|c|c|c|}
\hline \multirow[b]{2}{*}{ Centre } & \multirow[b]{2}{*}{$\mathbf{N}$} & \multicolumn{5}{|c|}{$\%$ haemodialysis } & \multicolumn{2}{|c|}{$\%$ peritoneal dialysis } \\
\hline & & Total & Home & Geo-HDD ${ }^{c}$ & Hospital & Satellite & CAPD & APD \\
\hline \multicolumn{9}{|l|}{ England } \\
\hline B Heart & 471 & 89.2 & 2.8 & 2.7 & 80.5 & 5.9 & 4.7 & 6.2 \\
\hline B QEH & 1,149 & 87.6 & 4.4 & 3.7 & 12.1 & 71.2 & 4.1 & 8.3 \\
\hline Basldn & 198 & 82.3 & 0.5 & 1.0 & 64.7 & 17.2 & 7.6 & 10.1 \\
\hline Bristol & 582 & 90.2 & 3.8 & 2.9 & 17.9 & 68.6 & 5.0 & 4.8 \\
\hline Carlis & 119 & 68.1 & 0.0 & 0.0 & 47.9 & 20.2 & 12.6 & 17.7 \\
\hline Carsh & 930 & 87.9 & 3.1 & 3.5 & 19.1 & 65.6 & 2.6 & 9.6 \\
\hline Chelms & 171 & 84.2 & 0.0 & 0.6 & 84.2 & 0.0 & 8.8 & 7.0 \\
\hline Colchr & 120 & 100.0 & 0.0 & 0.0 & 100.0 & 0.0 & 0.0 & 0.0 \\
\hline Dudley & 229 & 75.1 & 5.7 & 8.0 & 43.7 & 25.8 & 15.7 & 8.7 \\
\hline Exeter & 516 & 84.3 & 1.0 & 1.0 & 10.3 & 73.1 & 5.8 & 9.9 \\
\hline Glouc & 265 & 86.0 & 1.9 & 3.0 & 64.5 & 19.6 & 3.4 & 10.6 \\
\hline Hull & 434 & 82.5 & 1.8 & 2.5 & 41.5 & 39.2 & 10.6 & 6.9 \\
\hline Ipswi & 181 & 79.0 & 0.0 & 0.0 & 68.5 & 10.5 & 8.8 & 12.2 \\
\hline Kent & 484 & 87.6 & 3.3 & 3.9 & 25.4 & 58.9 & 10.3 & 2.1 \\
\hline L Barts & 1,214 & 83.0 & 1.9 & 1.7 & 35.3 & 45.8 & 1.8 & 15.2 \\
\hline L Guys & 709 & 95.4 & 6.9 & 3.4 & 11.9 & 76.6 & 2.0 & 2.7 \\
\hline L Kings & 656 & 86.3 & 1.8 & 3.0 & 16.9 & 67.5 & 5.8 & 7.9 \\
\hline L Rfree & 867 & 82.2 & 2.4 & 2.8 & 2.2 & 77.6 & 6.5 & 11.3 \\
\hline L St.G & 388 & 87.4 & 1.0 & 1.8 & 36.6 & 49.7 & 4.1 & 7.0 \\
\hline Norwch & 376 & 89.9 & 6.7 & 6.6 & 51.1 & 32.2 & 9.8 & 0.3 \\
\hline Nottm & 470 & 82.6 & 6.2 & 7.0 & 38.1 & 38.3 & 7.0 & 10.4 \\
\hline Oxford & 533 & 82.4 & 3.6 & 2.9 & 30.2 & 48.6 & 3.9 & 13.7 \\
\hline Plymth & 172 & 79.7 & 4.1 & 4.2 & 66.3 & 9.3 & 8.1 & 12.2 \\
\hline Ports & 739 & 90.3 & 7.6 & 7.2 & 18.9 & 63.7 & 9.7 & 0.0 \\
\hline Prestn & 626 & 91.5 & 6.4 & 6.5 & 20.5 & 64.7 & 1.6 & 6.9 \\
\hline Redng & 368 & 82.1 & 1.4 & 2.6 & 38.9 & 41.9 & 13.0 & 4.6 \\
\hline Salford & 483 & 82.4 & 3.1 & 4.1 & 24.2 & 55.1 & 6.2 & 11.4 \\
\hline Sheff & 601 & 90.2 & 7.2 & 6.6 & 36.6 & 46.4 & 9.8 & 0.0 \\
\hline Shrew & 235 & 86.4 & 9.8 & 11.5 & 42.1 & 34.5 & 5.5 & 8.1 \\
\hline Stevng & 525 & 97.0 & 4.4 & 4.4 & 26.3 & 66.3 & 2.9 & 0.0 \\
\hline Sthend & 143 & 88.1 & 1.4 & 2.1 & 86.7 & 0.0 & 11.9 & 0.0 \\
\hline Stoke & 409 & 81.7 & 8.1 & 7.2 & 48.9 & 24.7 & 2.4 & 10.0 \\
\hline Sund & 239 & 92.5 & 0.8 & 1.3 & 68.2 & 23.4 & 4.2 & 3.4 \\
\hline Truro & 183 & 88.0 & 5.5 & 5.5 & 39.9 & 42.6 & 5.5 & 6.6 \\
\hline Wirral & 206 & 90.8 & 5.8 & 6.3 & 37.9 & 47.1 & 1.5 & 7.8 \\
\hline Wolve & 397 & 80.1 & 5.8 & 6.9 & 43.8 & 30.5 & 7.3 & 11.1 \\
\hline York & 189 & 84.7 & 5.8 & 5.4 & 32.8 & 46.0 & 4.8 & 10.6 \\
\hline
\end{tabular}


Table 2.16. Continued

\begin{tabular}{|c|c|c|c|c|c|c|c|c|}
\hline \multirow[b]{2}{*}{ Centre } & \multirow[b]{2}{*}{$\mathbf{N}$} & \multicolumn{5}{|c|}{$\%$ haemodialysis } & \multicolumn{2}{|c|}{$\%$ peritoneal dialysis } \\
\hline & & Total & Home & Geo-HDD ${ }^{c}$ & Hospital & Satellite & CAPD & APD \\
\hline \multicolumn{9}{|l|}{ N Ireland } \\
\hline Antrim & 142 & 85.9 & 1.4 & 2.8 & 84.5 & 0.0 & 0.7 & 13.4 \\
\hline Belfast & 207 & 88.4 & 4.4 & 2.9 & 84.1 & 0.0 & 1.0 & 10.6 \\
\hline Newry & 110 & 80.0 & 2.7 & 2.9 & 77.3 & 0.0 & 0.9 & 19.1 \\
\hline Ulster & 113 & 94.7 & 1.8 & 2.6 & 92.9 & 0.0 & 0.0 & 5.3 \\
\hline West NI & 135 & 91.1 & 3.0 & 2.9 & 88.2 & 0.0 & 0.0 & 8.2 \\
\hline \multicolumn{9}{|l|}{ Scotland } \\
\hline Abrdn & 244 & 89.4 & 2.1 & 2.0 & 87.3 & 0.0 & 6.6 & 4.1 \\
\hline Airdrie & 211 & 92.4 & 0.0 & 1.4 & 92.4 & 0.0 & 2.4 & 5.2 \\
\hline D \& Gall & 65 & 83.1 & 4.6 & 4.7 & 78.5 & 0.0 & 13.9 & 3.1 \\
\hline Dundee & 204 & 91.7 & 1.0 & 1.0 & 90.7 & 0.0 & 5.9 & 2.5 \\
\hline Edinb & 311 & 91.3 & 1.9 & 2.2 & 89.4 & 0.0 & 2.6 & 6.1 \\
\hline Glasgw & 660 & 91.7 & 3.9 & 3.4 & 87.7 & 0.0 & 1.8 & 6.5 \\
\hline Inverns & 106 & 87.7 & 2.8 & 3.7 & 84.9 & 0.0 & 6.6 & 5.7 \\
\hline Klmarnk & 173 & 78.6 & 5.8 & 5.2 & 72.8 & 0.0 & 1.2 & 20.2 \\
\hline Krkcldy & 170 & 88.2 & 0.0 & 0.0 & 88.2 & 0.0 & 1.2 & 10.6 \\
\hline \multicolumn{9}{|l|}{ Wales } \\
\hline Bangor & 99 & 84.9 & 15.2 & 17.1 & 51.5 & 18.2 & 7.1 & 8.1 \\
\hline Cardff & 576 & 86.3 & 4.9 & 4.7 & 12.7 & 68.8 & 9.7 & 4.0 \\
\hline Clwyd & 104 & 80.8 & 6.7 & 4.0 & 74.0 & 0.0 & 4.8 & 14.4 \\
\hline Swanse & 427 & 85.5 & 8.4 & 8.5 & 44.3 & 32.8 & 7.7 & 6.8 \\
\hline Wrexm & 149 & 75.2 & 3.4 & 2.8 & 58.4 & 13.4 & 0.7 & 24.2 \\
\hline England & 23,731 & 87.3 & 4.3 & & 32.2 & 50.8 & 5.6 & 7.0 \\
\hline N Ireland ${ }^{\mathrm{a}}$ & 707 & 88.1 & 2.8 & & 85.3 & 0.0 & 0.6 & 11.2 \\
\hline Scotland ${ }^{\mathrm{b}}$ & 2,144 & 89.7 & 2.6 & & 87.1 & 0.0 & 3.4 & 7.0 \\
\hline Wales & 1,355 & 84.3 & 6.7 & & 35.2 & 42.4 & 7.5 & 8.2 \\
\hline UK & 27,937 & 87.3 & 4.2 & & 37.9 & 45.2 & 5.4 & 7.2 \\
\hline
\end{tabular}

${ }^{\mathrm{a}}$ There are no satellite units in Northern Ireland

${ }^{\mathrm{b}}$ All haemodialysis patients in Scotland are shown as receiving treatment at home or in centre as no data was available regarding satellite dialysis

'Geo-HHD: home haemodialysis presented by the centre closest to the patient's home postcode rather than the centre returning the data to the UKRR

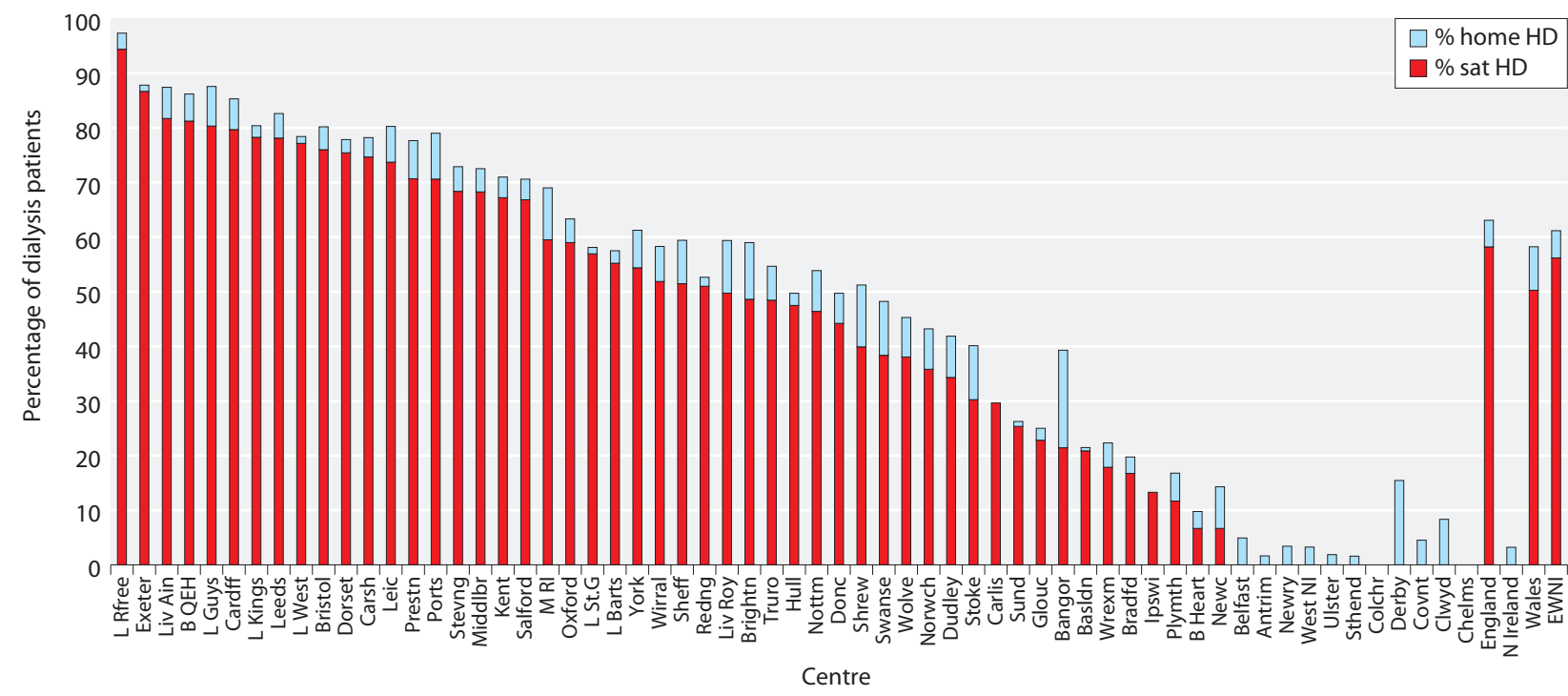

Fig. 2.8. Percentage of prevalent haemodialysis patients treated with satellite or home haemodialysis by centre on $31 / 12 / 2015$ * Scottish centres excluded as information on satellite HD was not available. No centres in Northern Ireland have satellite dialysis units 


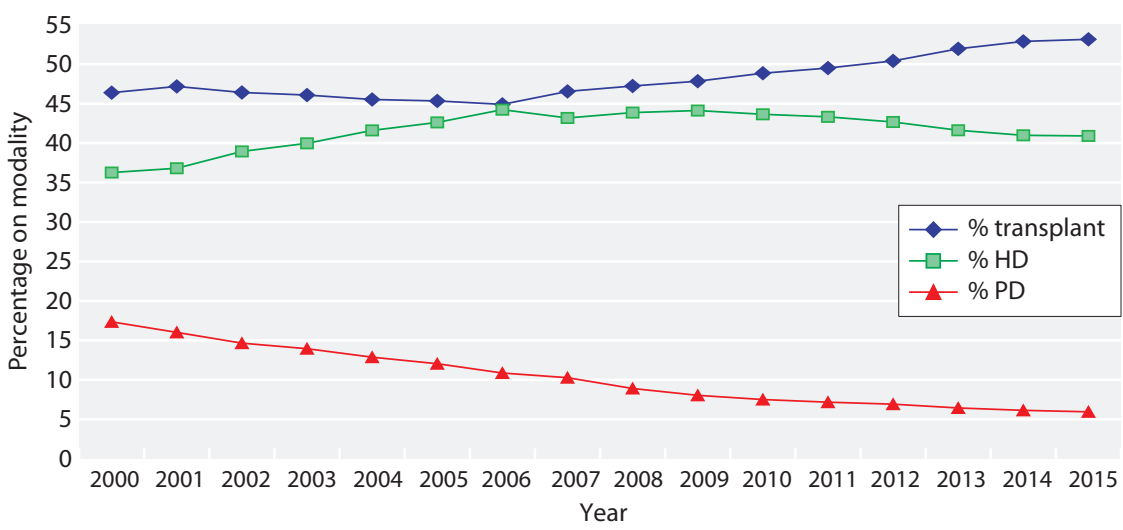

Fig. 2.9. Modality changes in prevalent RRT patients from 2000-2015 in Northern Ireland nearly all PD patients were on APD, across the UK six of the 69 centres with a PD programme did not report having any patients on APD.

\section{Home haemodialysis}

In 2015, the percentage of dialysis patients receiving home HD varied from $0 \%$ in six centres, to greater than $5 \%$ in 23 centres (table 2.16). In the UK, the overall percentage of dialysis patients receiving home haemodialysis has increased from $2.9 \%$ in 2010 to $4.2 \%$ in 2015.

The proportion of dialysis patients receiving home haemodialysis was greatest in Wales at $6.7 \%$, compared with $2.8 \%$ in Northern Ireland, $4.3 \%$ in England and $2.6 \%$ in Scotland (figure 2.8, table 2.16). By comparison, in 2007, the proportion of patients receiving home haemodialysis was $2 \%$ in each of the four UK countries. More recently, thirty-five renal centres across the UK had an increase in the proportion of individuals on home haemodialysis compared with 2014.

Some patients are sent by their parent renal centre to centres known to have a strong programme for home HD. In order to avoid the possibility of the parent renal centre being wrongly penalised, the proportion of patients on home HD was measured by centre, by assigning the patients to a given centre based on the patient postcode, rather than to the centre that returned the data to the UKRR (table 2.16-Geo-HHD). This showed an increase in the prevalence of $>1 \%$ of the home HD for some centres (Doncaster, Dorset, Dudley, Gloucester, London Kings, Liverpool Aintree, Reading, Shrewsbury, Wolverhampton, Antrim, Airdrie and Bangor).

\section{Change in modality}

The relative proportion of RRT modalities in prevalent patients has changed dramatically over the past 16 years. The main features are depicted in figure 2.9, which describes a year on year decline in the proportion of patients treated by PD since 2000 and a drop of $6.1 \%$ over the last 10 years. The absolute number of patients on PD decreased from 4,471 patients in 2005 to 3,545 patients in 2015. Time on PD has decreased over the last six years, from a median of 2.0 years in 2007 to 1.6 years in 2015 probably reflecting increased transplantation rates in this largely younger patient group and reducing technique survival rates. The percentage of patients undergoing PD for more than seven years was only $8.6 \%$.

The proportion of all RRT patients being treated with HD has fallen slightly since 2009 from $44.1 \%$ to $40.9 \%$ though this still represents an increase in absolute numbers on HD (from 21,671 to 25,024) as well as an increase in HD prevalence (from 354 to $384 \mathrm{pmp}$ ).

The proportion of patients with a functioning transplant has been increasing since 2007 (46.5\%) to 53.1\% in 2015. This probably reflects both an increasing number of incident transplants (2,218 adults and children in 2007 [2] to 3,174 in 2015) as well as increasing survival of prevalent transplant patients.

Figure 2.10 depicts in more detail the modality changes in the prevalent dialysis population during this time. The data show a clear reduction in patients treated by CAPD over time and an increase in satellite HD coupled with a reduction in hospital HD.

\section{International comparisons}

There are marked differences in RRT prevalence between countries (figure 2.11). RRT prevalence in Northern European countries (including the UK), Australia and New Zealand was lower than in Southern Europe which was lower than the USA and Canada.

Nephron 2017;137(suppl1):45-72 

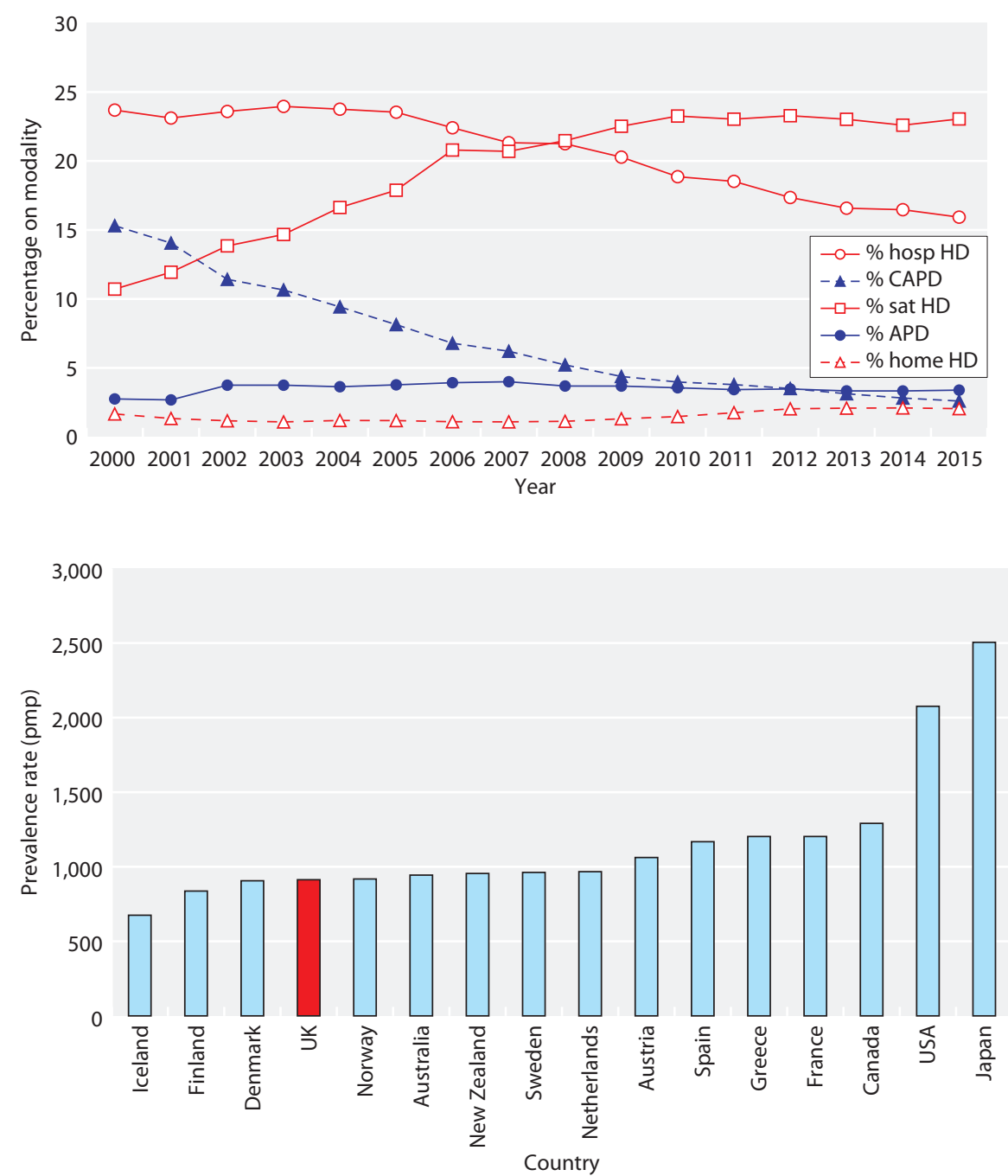

Fig. 2.10. Detailed dialysis modality changes in prevalent RRT patients from 2000-2015 *Scottish centres excluded as information on satellite HD was not available
Fig. 2.11. RRT Prevalence (pmp) by country in 2014

Non-UK data from USRDS available at https://www.usrds.org/2016/view/v2_13.aspx The UK data include paediatric patients to correspond with the data from the other countries.

All rates unadjusted. Japan is dialysis only. Data for France include 22 regions. Data for Spain include 18 of 19 regions. Data for Canada excludes Quebec.
Identifying the source of these differences is complicated by differences in healthcare systems, patient registry coverage and definitions (for example, data from Japan only includes dialysis), approaches to conservative care and incidence rates in these countries.

\section{Discussion}

The proportion of adults undergoing RRT continued to grow across all countries in the UK and there was an increase of $4 \%$ on 2014 in the UK as a whole.

Whilst half of all patients on RRT continued to be aged 40-64 years, the prevalent population is becoming more elderly with $16 \%$ of patients being over 75 years compared to $15.1 \%$ in 2010 . This is most noticeable in transplant patients where $31 \%$ of over 65 year old patients had a working transplant in 2015 compared to $23.7 \%$ in 2010.

The proportion of patients using peritoneal dialysis has been falling since the early 1990s and was just 6\% in 2015.

There were large variations in RRT prevalence between CCG/HB across the UK. This variation will largely be determined by the number of patients needing RRT but also by the clinical care delivered by renal centres. Many factors unrelated to clinical care will also have contributed to these differences such as geography, local population density, age distribution, ethnic composition, prevalence of diseases predisposing to kidney disease and the social deprivation index of that population. Comparisons with previous years was hindered somewhat by changes in the lower super output areas (LSOAs) 'covered' by each CCG as well as the combining of CCGs (in 2015 Gateshead CCG, Newcastle North and East CCG and Newcastle West CCG merged). 
The percentage of $\mathrm{CCG} / \mathrm{HB}$ areas with prevalence ratios as expected for the age and gender distribution of each area has increased over the last five years with fewer areas having higher than expected ratios. The reorganisations seen in healthcare areas over this same time period make interpretation of this finding more difficult. There remained large variations in the numbers of patients receiving RRT in each health area in the UK and the effects of centralising specialist commissioning arrangements in England on this variation will be seen in subsequent years.

\section{References}

1 Office for National Statistics. www.statistics.gov.uk

2 Webb, L., et al., UK Renal Registry 13th Annual Report: Chapter 3 Demographic and biochemistry profile of kidney transplant recipients in the UK in 2009: national and centre-specific analyses. Nephron Clin Pract. 2011; 119 (suppl 2): c53-84. doi: 10.1159/000331745

\section{Acknowledgement}

The (non-UK) data reported in the section on International comparisons have been supplied by the United States Renal Data System (USRDS). The interpretation and reporting of these data are the responsibility of the author(s) and in no way should be seen as an official policy or interpretation of the U.S. government.

Conflicts of interest: the authors declare no conflicts of interest 
